\title{
Statistical Modeling of Phenotypic Plasticity under Abiotic Stress in Triticum durum L. and Triticum aestivum L. Genotypes
}

\author{
Abdullah A. Jaradat \\ 1 United States Department of Agriculture-Agricultural Research Service (USDA-ARS), Iowa Avenue, Morris, \\ MN 56267, USA; abdullah.jaradat@ars.usda.gov; Tel.: +1-320-585-8441 \\ 2 Department of Agronomy and Plant Genetics, University of Minnesota, 803 Iowa Avenue, Morris, MN \\ 56267, USA
}

Received: 19 July 2018; Accepted: 2 August 2018; Published: 4 August 2018

\begin{abstract}
Future challenges to the role of durum and bread wheat in global food security will be shaped by their potential to produce larger yields and better nutritional quality, while increasingly adapting to multiple biotic and abiotic stresses in the view of global climate change. There is a dearth of information on comparative assessment of phenotypic plasticity in both wheat species under long-term multiple abiotic stresses. Phenotypic plasticities of two durum and bread wheat genotypes were assessed under increasing abiotic and edaphic stresses for six years. Combinations of normal and reduced length of growing season and population density, with or without rotation, generated increasing levels of competition for resources and impacted phenotypic plasticity of several plant and yield attributes, including protein and micronutrients contents. All the phenotypic plasticity (PPs) estimates, except for the C:N ratio in both genotypes and grain protein content in T. aestivum genotype, were impacted by abiotic stresses during the second stress phase (PS II) compared with the first (PS I); whereas, covariate effects were limited to a few PPs (e.g., biomass, population density, fertile tillers, grain yield, and grain protein content). Discrimination between factor levels decreased from abiotic phases $>$ growth stages $>$ stress treatments and provided selection criteria of trait combinations that can be positively resilient under abiotic stress (e.g., spike harvest and fertility indices combined with biomass and grain yield in both genotypes). Validation and confirmatory factor models and multiway cluster analyses revealed major differences in phenotypic plasticities between wheat genotypes that can be attributed to differences in ploidy level, length of domestication history, or constitutive differences in resources allocation. Discriminant analyses helped to identify genotypic differences or similarities in the level of trait decoupling in relation to the strength of their correlation and heritability estimates. This information is useful in targeted improvement of traits directly contributing to micronutrient densities, yield components, and yield. New wheat ideotype(s) can be designed for larger grain yield potential under abiotic stress by manipulating yield components that affect kernels $\mathrm{m}^{-2}$ (e.g., number of tillers, number of florets per spikelet, and eventually spike fertility and harvest indices) without impacting nutrient densities and kernel weight, thus raising harvest index beyond its current maximum.
\end{abstract}

Keywords: abiotic stress; micronutrients; latent variables; plasticity; wheat; yield components

\section{Introduction}

The dramatic transformation of wheat production due to unprecedented productivity growth from the Green Revolution benefited both producers and consumers of wheat through low production costs and low food prices [1]. However, future challenges to the role of wheat in global food security will be shaped by its potential to produce larger yields and better nutritional quality, while increasingly 
withstanding multiple biotic and abiotic stresses [2,3]. Slowing productivity growth, which is caused by biotic and abiotic stresses, is further complicated by changing consumption patterns and the growing demand for diverse and more nutritious wheat products in the developing world [1,4]. Average annual growth rate for the Unites States (US) and Canada during the last 15 years was $1.65 \%$ with a negative area growth rate of $-1.25 \%$, negative consumption of $-1.06 \%$, and a modest average yield of $2.97 \mathrm{Mg} \mathrm{ha}^{-1}[1]$.

Wheat genotypes with improved adaptation to abiotic stresses are required to satisfy increasing demand for more quantity and better quality of wheat products [2], especially protein content and micronutrient density [5]. Renewed interest in phenotypic plasticity (PP) in agronomic research led to fresh insights into the complex relationships among yield components [6,7]; and, their association with phenological and architectural traits, expressed, respectively, by growing degree days, GDD; and, fractal dimension, Do [8,9]. To assess the benefit or cost of plasticity in wheat, it is imperative to estimate the relationship between a trait plasticity and grain yield per se, as well as other traits that are associated with grain yield $[10,11]$. Grain yield depends largely on resource allocation to different parts of the wheat plant $[12,13]$. In turn, resource allocation may influence nearly all major structures and functions of the wheat plant; is affected by a range of interacting physiological pathways; is temporally variable; and, interacts with several environmental factors [14]. Remarkably, large diversity of phenotypically plastic strategies evolved in response to changes in resource availability caused either by climate change or management practices [15].

A wide range of phenotypically plastic strategies evolved in response to changes in resource availability for T. durum under Mediterranean climate $[4,16]$ and for T. aestivum under continental climate $[17,18]$. Under both climates, natural selection usually favored the evolution of a phenotypically plastic resource allocation when the optimal resource allocation strategy changes due to resource availability [12]. Differences between durum and bread wheat, which are mainly attributed to evolution under domestication, intensity of breeding and selection [16], and eco-geographical adaption (i.e., Mediterranean vs. Continental) [10,19], have been documented in a few studies [20]. However, assessment of biomass, and potential grain yield and its components (e.g., tillers, kernels $\mathrm{m}^{-2}$ and 1000-kernel weight) in response to abiotic stresses, such as water deficit [21] and micronutrient deficiencies [22], are of increasing interest to wheat scientists. Grain yield of wheat under abiotic stress can be explained by traits that are fully independent of the species (e.g., durum and bread wheat) or genotypic response to stress environment [19,20,23]; therefore, it is important to properly separate plasticity of constitutive (e.g., kernel weight) from adaptive (e.g., kernels $\mathrm{m}^{-2}$ ), maladaptive (e.g., plant height), or neutral (e.g., days to maturity) traits in search for high yielding wheat under abiotic stress. High-yielding wheat genotypes are expected to exhibit strong PP, particularly in number of fertile tillers and spike size. Alternatively, wheat genotypes (and species, e.g., einkorn, emmer, or spelt) with a high survival rate under increasing abiotic stress, but with low PP, might be of value to farmers under future climate change $[17,19,24]$.

Phenotypic plasticity, as an antipode to stability, is a mechanism by which single plants in a crop adjust their expressed trait values in architectural and physiological functions, thereby responding dynamically to abiotic stresses that are caused by resource (in) availability, mainly light, water, and nutrients [10,25-27]. The classical concept of PP [28] indicates that a range of phenotypes is produced by a single genotype under varying environmental conditions. However, the ability of different genotypes (e.g., in a landrace) that can assume the same phenotype is an alternative form of PP [29]. In this case, a population may maintain a practical level of genetic diversity while exhibiting a relatively similar level of phenotypic expression under varying field condition. Additionally, plasticity at a population level may be used as a statistical measure of average differences among environments across genotypes $[19,30]$. Nevertheless, when expressed at a population level, plasticity is a statistical measure of how the across-genotypes phenotypic mean of a trait changes with abiotic stress [30].

Phenotypic plasticity of wheat plants in response to abiotic stresses is important for adapting to a changing climate; therefore, future wheat genotypes need to be more flexible and adaptable to abiotic 
stresses and exhibit larger levels of plasticity to environmental diversity $[4,5,17]$. Wheat plants under dryland production systems experience complex multidimensional and spatiotemporal environments, therefore, wheat scientists are keenly interested in understanding the mechanisms of plant response to single and multiple abiotic stresses [20,24,31]. Resource limitations due to abiotic stress, in addition to field spatial heterogeneity, impact wheat yield, due to intra-population competition [32]. However, common occurrence of interactions (i.e., non-additivity) between plant responses to abiotic stress (e.g., limiting water, light, and nutrients resources) [8], and the complexity and trait-specific mechanisms of such responses make it difficult to extrapolate from single to multiple abiotic stress scenarios $[9,33]$. Additionally, recent empirical studies exploring the effects of growth stage on plasticity suggested that a plastic response at an earlier growth stage (e.g., nutrient stress at seedling stage) might adjust (in magnitude or direction) the ability of a plant or population to respond to future abiotic stress at a latter growth stage $[21,22,33]$.

The wheat phenotype is a dynamic and plastic system of successive processes of organ initiation, differentiation, resource capture, growth, reproduction, recycling of internal carbon and nutrient resources (i.e., C:N ratio as indicator of their coupling, yield), and senescence $[4,7,18,34]$. The remarkable stability of this performance across diverse environments and population densities in the absence of physiological stresses is a result of adaptive plasticity, or compensatory growth, of sequentially initiated and inter-dependent yield components $[6,7,35]$. Recent reports $[7,22]$ attributed the stability of wheat yield to greater plasticity of its component traits, especially harvest index (HI), which is approaching its physiological limits $[35,36]$. Since the early 1990s, almost no systematic progress in HI was achieved; therefore, future yield gains will depend more on increased biomass, which demonstrated a close association with higher grain yield [3,19,24].

A larger magnitude of association between yield plasticity and maximum grain yield, as opposed to a much smaller one that is associated with minimum grain yield, indicates that larger plasticity is favored under optimal conditions, without a yield penalty under low-yielding conditions [11,37]; thus, negating the classical attitude towards large phenotypic diversity as a negative trait because of its association with low grain yield under low-yielding conditions [38]. Nevertheless, genotypes with higher yield potential generally express their advantage under a wide range of suboptimal environments [39]. Large grain yield plasticity is often associated with short plants, less lodging, more kernels $\mathrm{m}^{-2}$, lower grain protein content (grain protein content), late maturity, and large kernel weight $[7,37]$. Associations between plasticity estimates of these traits are typically, but not always, positive. In the case of durum and bread wheat, and regardless of clear differences between these species in kernels $\mathrm{m}^{-2}$, and kernel weight, their yield responses to abiotic stress are independent of the latter and are exclusively mediated by the former yield component [40].

Recent advances in phenotyping made it possible to streamline quantitative measurements and qualitative description of large numbers of crop plants and their yield components [29]. This was achieved despite negative relationships between phenotypic plasticity and heritability estimates of yield components due to the collective effects of strong environmental impact, genetic and physiological controls, and evolutionary constraints [36,41], which may restrict their value in breeding [16] and agronomic applications [41]. In such case, phenotypic plasticity, as a measure of how a wheat genotype may respond to the environment, could impact important quality traits, such as protein content and micronutrients density [11,42], especially of high-yielding wheat genotypes [43].

Objectives of this study were to (1) conduct a comprehensive assessment of differences between a T. durum and a T. aestivum genotype at the reproductive and full maturity stages; (2) estimate variance components, $\mathrm{PP}$, and their heritability estimates for yield, yield components, and micronutrients; (3) build calibration and validation models for micronutrient densities under abiotic stresses; and, (4) estimate regression and correlation coefficients in confirmatory factor analyses to integrate the effects at the start (no stress) and end (extreme stress) of abiotic stress six-year field experiment for each wheat genotype. 


\section{Materials and Methods}

A multi-year (2006-2011), multi-species (two Triticum spp. and two genotypes each of Carthemus tinctorius L., Cicer aerietinum L., Glysin max (L.) Merr., and Zea maize L.) field experiment was conducted to evaluate intra- and inter-specific variation under abiotic stress [43]. This part of the study reports on the phenotypic plasticity of one genotype each of Triticum aestivum and T. durum species under three levels of abiotic stress as compared to no-stress control during six years of field studies (Table 1).

Table 1. Design of a factorial field experiment evaluating durum (T. durum; cv. "Alsen") and bread (T. aestivum; cv. "Lebsock") wheat genotypes in a randomized complete plot design, including abiotic stress phases, treatments, factors, meteorological data, and experimental units for six years (2006-2011).

\begin{tabular}{|c|c|c|c|c|c|c|c|}
\hline Factors & \multicolumn{7}{|c|}{ Abiotic Stress Treatments } \\
\hline \multirow[t]{4}{*}{ Stress phase (SP) } & \multicolumn{3}{|c|}{ SP I (2006-2008) } & \multicolumn{4}{|c|}{ SP II (2009-2011) } \\
\hline & \multirow{3}{*}{\multicolumn{3}{|c|}{$\begin{array}{l}\text { Normal length of growing season/Normal } \\
\text { population density (NN, Control) } \\
25 \% \text { Shorter growing season than } \\
\text { normal/Normal population density (SN) }\end{array}$}} & \multicolumn{4}{|c|}{$\begin{array}{l}\text { Normal length of growing season } / 25 \% \text { Higher } \\
\text { population density than normal (NH) }\end{array}$} \\
\hline & & & & \multirow{2}{*}{\multicolumn{4}{|c|}{$\begin{array}{l}25 \% \text { Shorter growing season than normal } / 25 \% \\
\text { Higher population density than normal (SH) }\end{array}$}} \\
\hline & & & & & & & \\
\hline Crop rotation & \multicolumn{3}{|c|}{ Continuous wheat } & \multicolumn{4}{|c|}{ Wheat rotated with soybean } \\
\hline Genotypes/cultivars & \multicolumn{7}{|c|}{ T. aestivum, cv. "Alsen" and T. durum, cv. "Lebsock" } \\
\hline Main plot dimensions (m) & \multicolumn{7}{|c|}{$6 \times 12$} \\
\hline Sampling sub-plots $\left(\mathrm{m}^{2}\right)$ & \multicolumn{7}{|c|}{0.5} \\
\hline Sowing Julian date & \multicolumn{7}{|c|}{$110 \pm 5$} \\
\hline Samples/genotype/year & \multicolumn{7}{|c|}{$80-100$} \\
\hline Variables & \multicolumn{7}{|c|}{ Year } \\
\hline $\begin{array}{l}\text { Weather variables; } 100 \text { years } \\
\quad(\text { mean } \pm \text { SD) }\end{array}$ & 2006 & 2007 & 20 & & 2009 & 2010 & 2011 \\
\hline Rainfall, mm $(589 \pm 87)$ & 460 & 550 & & & 450 & 570 & 550 \\
\hline $\begin{array}{c}\text { Growing degree days }(1930 \pm 190) \\
{ }^{\circ} \mathrm{C}\end{array}$ & 1950 & 1940 & 18 & & 1895 & 1920 & 1900 \\
\hline Temperature $(14.7 \pm 2.8)^{\circ} \mathrm{C}$ & $17.9 \pm 4.6$ & $18.2 \pm 4.2$ & 16.1 & 3.9 & $17.4 \pm 4.2$ & $17.8 \pm 4.2$ & $17.4 \pm 4.7$ \\
\hline $\begin{array}{l}\text { Photothermal quotient }(1.84 \pm 0.5) \\
\qquad \mathrm{MJ} \mathrm{m} \mathrm{m}^{-2} \text { day }^{-1}{ }^{\circ} \mathrm{C}^{-1}>0.0\end{array}$ & $1.47 \pm 0.7$ & $1.95 \pm 0.8$ & 1.85 & & $1.75 \pm 0.6$ & $1.68 \pm 0.5$ & $1.69 \pm 0.7$ \\
\hline
\end{tabular}

\subsection{Experimental Design}

A factorial experiment in a randomized complete block design, with three replicates, was established at the Swan Lake Research Farm, near Morris, MN, USA $\left(45^{\circ} 41^{\prime} \mathrm{N}, 95^{\circ} 48^{\prime} \mathrm{W}\right.$, and elevation $370 \mathrm{~m}$ ). The land area was previously uniformly planted with soybean to minimize spatial variability. The major soil series identified within the experimental site was Barnes loam (fine-loamy, mixed, superactive frigid Calcic Haplotoll) [44]. Average annual precipitation in this region was $645 \pm 53 \mathrm{~mm}$ and the average temperatures during the wheat growing season (June-August) ranged from $15.3^{\circ} \mathrm{C}$ in April to $26.7^{\circ} \mathrm{C}$ in August [45].

Full factorial combinations of two wheat genotypes, one each of T. aestivum, (cv. "Alsen") and T. durum, (cv. "Lebsock"); normal (1800 \pm 54 GDD) and short (1350 \pm 48 GDD) length of the growing season in growing degree days for the period 2006-2011; and, two population densities (normal: 450 live seed $\mathrm{m}^{-2}$ and high: 560 live seed $\mathrm{m}^{-2}$ ). The same factorial treatment combinations were maintained on each experimental plot for the first three years (2006-2008) to enforce additional edaphic stress on the crop (SP I), then wheat was rotated with soybean in a two-year rotation during the next three years (2009-2011) to release the edaphic stress (SP II), while maintaining the same levels of other abiotic stresses as in SP I (Table 1). The shorter growing season deprived the wheat plants from fully utilizing inputs for full development, and the larger population density created more competition for inputs and natural resources. Land management that is typical of wheat husbandry (tillage, planting depth, weed control) in the Upper Midwest was followed during the duration of the experiment. Fertility management (N, P, K rate, method, and time of application) was based on annual soil analysis. Sampling sub-plots were selected every year to represent the average stand in each of wheat genotype-population density-length of the growing season-growth stage factorial combinations. Land dimensions of each experimental plot accommodating a factorial combination were $6.0 \times 12.0 \mathrm{~m}$, with $0.3 \mathrm{~m}$ between rows. 


\subsection{Covariates}

Three covariates were estimated or measured and used to adjust for spatiotemporal variation in the experimental area during the duration of the six-year field experiment; theses were, rows and columns of experimental plots, photothermal quotient (PTQ; $\mathrm{MJ} \mathrm{m} \mathrm{m}^{-2}$ day ${ }^{-1}{ }^{\circ} \mathrm{C}^{-1}$ ) prior to anthesis [35], and an integrated vertical and horizontal continuous measurements of soil electrical conductivity (ECa; $\mathrm{dS} \mathrm{m}^{-1}$ ) using EM-38 after emergence and after harvest [43].

Daily photothermal quotient (PTQ, the ratio of mean daily incident short-wave radiation to mean daily temperature more than $4.5^{\circ} \mathrm{C}$ ) was calculated, according to the following formulae [46].

$\mathrm{PTQ}=$ Solar radiation $/(T-4.5)\left(\right.$ If $T>10$; where $T=$ daily mean temperature, $\left.{ }^{\circ} \mathrm{C}\right)$, and PTQ $=$ Solar radiation $\times[(T-4.5) / 5.5] / 5.5$ (If $4.5<T<10$ ); otherwise, $\mathrm{PTQ}=0$, if $T<4.5$.

The growing degree days (GDD) were calculated [6] while using maximum (Tmax) and minimum (Tmin) daily temperatures and base temperature $\left(T b=4.5^{\circ} \mathrm{C}\right)$ as $[((\operatorname{Tmax}+\mathrm{Tmin}) / 2\}-\mathrm{Tb}]$.

\subsection{Sampling Protocol}

Wheat plants were monitored during the growing season to determine sampling time of biomass. Above ground biomass was sampled at GS69 (i.e., about 15 days after completion of anthesis) and at full maturity from permanent geo-referenced sampling sites $\left(0.15 \mathrm{~m}^{2}\right.$ from $50 \mathrm{~cm}$ length of three central adjacent rows) in each replicate, abiotic stress treatment, and year $[47,48]$. Number of plant samples per genotype per year ranged from 80 to 100 .

\subsection{Sample Processing}

Each sampling site was assessed for population density $\left(\right.$ plants $\mathrm{m}^{-2}$ ), number of fertile tillers per unit area, and number and weight of spikes. At each sampling stage, plant samples were separated into stems, leaves, and spikes, then dried in a forced-air oven at $60^{\circ} \mathrm{C}$ for $48 \mathrm{~h}$ and weighed. Grain weight and kernels $\mathrm{m}^{-2}$ at full maturity were estimated on three sub-samples from each sampling site and averaged for statistical analysis. Five spikes were randomly selected from each sampling site and growth stage was used to estimate spike harvest index (kernel weight/spike weight) and spike fertility index (kernels 100-spikelets ${ }^{-1}$ ). The relationship of grain yield (and its PP) with kernel weight is minimal $\left(R^{2}=0.07\right)$ when compared to that of kernels $\mathrm{m}^{-2}\left(R^{2}=0.85\right)$, therefore, and due to constitutive differences in kernel weight between T. durum and T. aestivum ( $\left.>10 \mathrm{mg} \mathrm{kernel}^{-1}\right)$, number of kernels $\mathrm{m}^{-2}$ was used in the current study. Carbon and nitrogen were determined on kernel samples as a percent of dry weight using LECO FP-428 analyzer (LECO, St. Joseph, MI, USA), and then the $\mathrm{C}: \mathrm{N}$ ratio was calculated. Percent nitrogen values were used to estimate crude protein content as $\mathrm{N} \%$ $\times 6.25$, while micronutrients $(\mathrm{Cu}, \mathrm{Fe}, \mathrm{Mn}$, and $\mathrm{Zn})$ determination was carried out using simultaneous ICP-OES (inductively coupled plasma-optical emission spectroscopy) instrument [42].

\subsection{Estimation of Phenotypic Plasticity}

The most direct method of estimating PP was used in the current study and it was based on the normalized variation of the phenotype (i.e., by expressing a trait value under stress as a ratio of its value under no-stress treatment and it can range from $0.0 \%$ to $100 \%$ ) [49-51]. However, the PP estimation method that was used in the current research returns results that are equivalent to those obtained by a common method to quantify PP, which involves models of phenotype vs. environment, where the parameter estimates of the functions are taken as a measure of plasticity [38].

\subsection{Data Management}

A database comprised of measured and estimated variables on plot-, plant-, and kernel-basis and classified by year, stress phase, growth stage, and abiotic stress factors, was compiled for 2006-2011, and was inspected for outliers as well as for univariate and multivariate normality. Nutrient concentrations were natural-log transformed; while, other traits were transformed following individual Box-Cox 
transformations to optimize normality when necessary, then back-transformed for reporting [52]. Percent change in PP $( \pm S D)$ was estimated annually for each trait in each wheat genotype as the normalized absolute difference between its value under the control and its value under each of the remaining abiotic stress treatments (e.g., $|\mathrm{NN}-\mathrm{SH}|$; i.e., the normalized variation of the phenotype). Phenotypic (PCV) and genotypic (GCV) coefficients of variation were estimated as $\left(\sqrt{ } \sigma^{2} p /\right.$ sample mean $) \times 100$; and, $\left(\sqrt{ } \sigma^{2} g /\right.$ sample mean $) \times 100$; respectively; then, the narrow-sense heritability was estimated for each trait as $h^{2}=\sigma^{2} g /\left[\sigma^{2} g+\left(\sigma^{2} g e / e\right)+\left(\sigma^{2} r / r e\right)\right]$, where $\sigma^{2} p$ is the phenotypic variance; $\sigma^{2} g$ is the variance of the genotype, $\sigma^{2} g e$ is the variance of the genotype $\times$ environment interaction, $\sigma^{2} r$ is the residual, $e$ is the number of environments, and $r$ is the number of replicates [13].

\subsection{Statistical Analyses and Modeling}

Univariate and multivariate statistical analyses procedures appropriate for generating, analyzing, and modeling primary or secondary statistics were employed in assessing the effects of single or multiple interacting factors on the PP of agronomic traits and micronutrients during six years of field testing. Frequency distribution, mean \pm SD for PP of agronomic traits averaged over six-years were plotted for each wheat genotype and stress phase; the variance accounted for by differences between stress phases was estimated and reported, as adjusted $R^{2}$ calculated as $1-\left[\left(1-R^{2}\right) \times n-1\right] /[n-k-$ $1]$; where $n$ is the number of data points and $k$ is the number of independent regressors (i.e., the number of variables in the model, excluding the constant) [53]. Box-plots (mean $\pm 95 \%$ confidence intervals) and mean separation were performed on phenotypic plasticities of biomass, population density, fertile tillers, grain yield, spike fertility index, spike harvest index, kernels $\mathrm{m}^{-2}$, grain protein content, and $\mathrm{C}: \mathrm{N}$ ratio, as well as micronutrients for wheat genotype-stress phase-growth stage-abiotic stress factorial combinations; mean separation was performed using Tukey's HSD $(p<0.05)$. A micronutrient index was calculated as percent of the largest cumulative micronutrients density.

As part of the statistical analyses, measured or estimated data were adjusted for covariate effects, and a generalized linear model (GLM) was used to estimate the effects of main factors and their two-way and three-way interactions on plasticity estimates of agronomic traits, C:N ratio, micronutrient densities, and their index. The probability of obtaining larger F-value for each test was used as an indicator of significant differences between factor levels; in which case, pair-wise significant percent differences (PSPD) were obtained from a matrix of mean separation probabilities of $[(n \times n-1) / 2]$, where $n$ is the number of means, using Tukey's HSD [53]. Summary statistics of the GLM included plasticity mean response (and its RMSE) to each factor and adjusted $R^{2}$. Hierarchical multi-way and multi-variate cluster analyses of standardized data, using Unweighted Pair Group Method with Arithmetic Mean (UPGMA) linkage and Ward variance methods [53], as well as discriminant analysis [54], were used to quantify trait relationships and the level of discrimination between sub-factors (i.e., percent correct classification of stress phases, growth stages, and levels of abiotic stress) for each wheat genotype.

Phenotypic plasticity estimates for each factor in the experiment where subjected to in-depth statistical analyses to explore the relationships and dependencies within and among independent (biomass, population density, fertile tillers, grain yield, spike harvest index, spike fertility index, kernels $\mathrm{m}^{-2}$, grain protein content, and $\mathrm{C}: \mathrm{N}$ ratio) and dependent $(\mathrm{Cu}, \mathrm{Fe}, \mathrm{Mn}$, and $\mathrm{Zn})$ variables at the bivariate and multivariate (i.e., matrix) levels. Data for independent variables were subjected to Factor analysis to quantify trait relationships within independent factors; Partial Least Squares Regression (PLSR) was used to model the relationship between dependent and independent variables; a validation step (using 30\% of data) was included to verify the utility of the developed PLSR model [53]. The resulting model coefficients for centered and scaled data were used to construct a correlation matrix between the independent variables for each sub-factor, which were then subjected to a Mantel test to quantify and test the significance of relationships at the matrix level $[55,56]$. Similarly, correlation matrices were developed for each sub-factor while using independent variables, and then were subjected to a Mantel test, as described before. Bivariate functional relationships between 
micronutrients within sub-factors were estimated using Major Reduced Axis (RMA), and then a Jackknifed $R^{2}$ value was estimated for these relationships [57]. A multivariate, non-dimensional distance (Mahalanobis $D^{2}$ ) was estimated between sub-factors within each factor in the experiment and then tested for significance [54]. Three latent variables were proposed to perform confirmatory factor analysis as a final step in multivariate analyses of $\mathrm{C}: \mathrm{N}, \mathrm{Cu}, \mathrm{Fe}, \mathrm{Mn}$, and $\mathrm{Zn}$ to explain the latent variable "Nutrients". A second variable set (fertile tillers, kernels $\mathrm{m}^{-2}$, spike fertility index, and spike harvest index) was used to explain the latent variable "Yield Components". A third set of variables (biomass, grain yield, and population density) was used to explain the latent variable "Yield." A confirmatory factor model (CFA) was developed for each of T. aestivum and T. durum using quantitative data summarized for the control (NN at SP I) and at the end of the experiment using summarized data for the double abiotic stress of short growing season and high population density (SH at SP II) [58].

\section{Results}

\subsection{Inter- and Intraspecific Variation in Phenotypic Plasticity}

Frequency distribution, range, and mean $\pm \mathrm{SD}$ of PP estimates of agronomic traits and micronutrients index assessed on two wheat genotypes representing T. durum and T. aestivum and then subjected to two stress phases are presented in Figure 1. Included is variance estimates $\left(R^{2}\right)$ accounted for by differences between abiotic stress phases. Most PPs were normally distributed when stress phases were not considered. A few PPs in T. durum were negatively (e.g., population density) or positively skewed (e.g., grain yield, and nutrient index). Slightly larger number of mean PPs were $\leq 0.75$ than those with mean PPs $>0.75$. Both of the wheat genotypes displayed a wide range of PPs (0.40-0.90) for biomass, population density, and micronutrients. The estimates for productive tillers and grain yield had narrow ranges (0.75-0.95), and a still narrower range was found for spike fertility index in both genotypes $(0.80-0.92)$. Large differences between wheat genotypes were found for kernels $\mathrm{m}^{-2}$ and the spike harvest index.

Frequency distributions for most PPs differed between both stress phases. Estimates during PS I exceeded their counterparts during PS II; however, with a few exceptions (e.g., kernels $\mathrm{m}^{-2}$ in T. durum). Minimum PPs for PS II (e.g., biomass) or substantially (e.g., population density and kernels $\mathrm{m}^{-2}$ in T. durum) were slightly larger than their counterparts during PS I. These differences contributed to the small $R^{2}(\leq 0.20)$ for biomass and population density in both genotypes. Also, they contributed to medium $\left(0.20>R^{2} \leq 0.50\right)$ for grain yield, spike fertility index, and micronutrient index (micronutrients index in both genotypes); and, to large variance estimates $(>0.50)$ for grain protein content in both genotypes, and for kernels $\mathrm{m}^{-2}$ in T. durum.

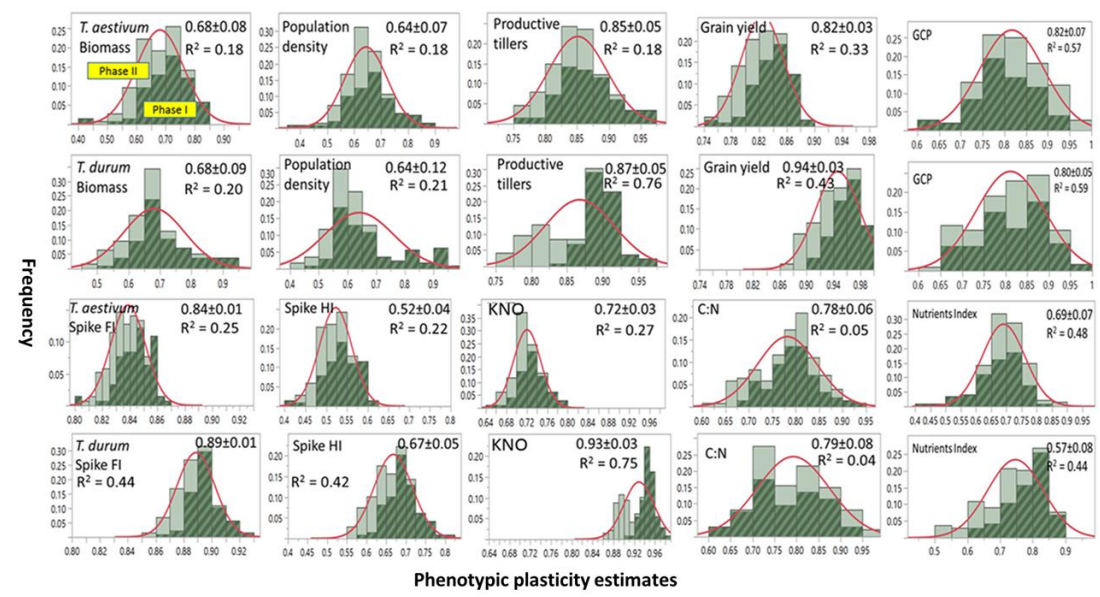

Figure 1. Frequency distribution (y-axis), range, and mean \pm SD of phenotypic plasticities ( $x$-axis) of agronomic traits and micronutrients index estimated on two genotypes representing T. durum and T. aestivum and then subjected to two stress phases, each of three years. 


\subsection{Assessment of Agronomic and Micronutrients PPs}

Test statistics that were derived from results of a GLM analysis, level of significance, and percent significant pair-wise differences between sub-factors; phenotypic and genotypic coefficients of variation and narrow-sense heritability of PPs of agronomic traits and micronutrients of T. aestivum and T. durum wheat genotypes attributed to fixed single factors and their interactions in a six-year field study under abiotic stress are presented in Table 2. The photo-thermal quotient (PTQ) was the most effective covariate, accounting for significant variances $\left(R^{2}, 0.34-0.72\right)$ in PPs of agronomic traits, with the exception of spike fertility index, and kernels $\mathrm{m}^{-2}$; the integrated soil conductivity measure (ECa) explained significant portions of variance in fertile tillers (0.21) and grain yield (0.35); while, the spatial variation, mediated by columns and rows of experimental plots as covariates, accounted for small (0.25) variance in grain yield; however, none of the covariates accounted for significant portions of variances in micronutrients index or $\mathrm{C}: \mathrm{N}$ ratio. 
Table 2. Test statistics derived from results of a generalized linear model analysis, level of significance and percent significant pair-wise comparisons (PSPD); phenotypic, genotypic variance components and narrow sense heritability estimates of plasticity estimates of agronomic traits and micronutrients of T. aestivum and T. durum wheat genotypes attributed to fixed single factors and their interactions in a 6-year field study under three abiotic stress levels as compared to non-stress treatment $(* * *$, significant at the $5 \%$ and $1 \%$ level of probability, respectively, using Tukey's HSD).

\begin{tabular}{|c|c|c|c|c|c|c|c|c|c|c|c|c|c|c|}
\hline \multirow[t]{2}{*}{ Covariates } & \multicolumn{8}{|c|}{ Plasticity of Agronomic Traits } & \multicolumn{6}{|c|}{ Plasticity of C:N and Micronutrients \& Their Index, MNI } \\
\hline & BM & PD & FT & GY & SFI & SHI & KNO & GPC & $\mathrm{C}: \mathrm{N}$ & $\mathrm{Cu}$ & $\mathrm{Fe}$ & $\mathrm{Mn}$ & $\mathrm{Zn}$ & MNI \\
\hline & \multicolumn{14}{|c|}{ Variance explained by covariate $\left(R^{2}\right)$} \\
\hline Photo thermal quotient $\left(R^{2}\right)$ & $0.69^{* *}$ & 0.56 ** & $0.72 * *$ & $0.62 * *$ & 0.25 & $0.34 *$ & 0.09 & $0.45^{*}$ & 0.05 & 0.11 & 0.09 & 0.07 & 0.05 & 0.06 \\
\hline Integrated $\mathrm{ECa}(\mathrm{H}$ and $\mathrm{V})$ & 0.15 & 0.09 & $0.21 *$ & 0.35 * & 0.08 & 0.08 & 0.00 & 0.00 & 0.0 & 0.0 & 0.0 & 0.0 & 0.0 & 0.0 \\
\hline GIS (Columns × Rows) & 0.14 & 0.0 & 0.07 & 0.25 * & 0.15 & 0.11 & 0.0 & 0.05 & 0.0 & 0.06 & 0.08 & 0.0 & 0.10 & 0.05 \\
\hline Fixed factors & \multicolumn{14}{|c|}{ Test statistics (Probability of $>\mathrm{F}$ due to fixed factor) } \\
\hline Genotypes & 0.47 & 0.83 & 0.26 & 0.001 & 0.001 & 0.001 & 0.001 & 0.01 & 0.30 & 0.05 & 0.009 & 0.001 & 0.013 & 0.02 \\
\hline PSPD & - & - & - & 100 & 100 & 100 & 100 & 100 & - & 100 & 100 & 100 & 100 & 100 \\
\hline Stress phases & 0.13 & 0.20 & 0.05 & 0.04 & 0.05 & 0.05 & 0.04 & 0.05 & 0.98 & 0.005 & 0.14 & 0.68 & 0.03 & 0.34 \\
\hline PSPD & & & 100 & 100 & 100 & 100 & 100 & 100 & & 100 & - & - & 100 & - \\
\hline Growth stages & 0.32 & 0.05 & 0.04 & 0.01 & 0.08 & 0.12 & 0.001 & 0.01 & 0.12 & 0.05 & 0.04 & 0.02 & 0.03 & 0.001 \\
\hline PSPD & & 100 & 100 & 100 & - & - & 100 & 100 & & 100 & 100 & 100 & 100 & 100 \\
\hline Abiotic stresses & 0.71 & 0.02 & 0.05 & 0.28 & 0.77 & 0.51 & 0.05 & 0.05 & 0.003 & 0.05 & 0.22 & 0.30 & 0.16 & 0.79 \\
\hline PSPD & - & 100 & 33 & - & - & - & 30 & 25 & 50 & 17 & - & - & - & - \\
\hline Genotypes $\times$ Stress phases & 0.81 & 0.26 & 0.05 & 0.05 & 0.05 & 0.05 & 0.04 & 0.05 & 0.05 & 0.04 & 0.35 & 0.01 & 0.88 & 0.05 \\
\hline PSPD & - & - & 33 & 67 & 67 & 67 & 67 & 25 & 10 & 67 & - & 30 & - & 30 \\
\hline Genotypes $\times$ growth stages & 0.82 & 0.05 & 0.05 & 0.05 & 0.05 & 0.05 & 0.001 & 0.01 & 0.05 & 0.001 & 0.05 & 0.001 & 0.021 & 0.001 \\
\hline PSPD & - & 16 & 33 & 50 & 50 & 50 & 75 & 25 & 17 & 83 & 82 & 82 & 83 & 50 \\
\hline Genotypes $\times$ Abiotic stresses & 0.001 & 0.05 & 0.05 & 0.001 & 0.001 & 0.001 & 0.001 & 0.01 & 0.001 & 0.05 & 0.001 & 0.001 & 0.001 & 0.001 \\
\hline PSPD & 100 & 7 & 25 & 70 & 64 & 70 & 72 & 50 & 35 & 10 & 50 & 82 & 56 & 72 \\
\hline Growth stage $\times$ abiotic stresses & 0.05 & 0.03 & 0.59 & 0.07 & 0.11 & 0.09 & 0.02 & 0.08 & 0.05 & 0.91 & 0.05 & 0.03 & 0.21 & 0.21 \\
\hline PSPD & 18 & 18 & & - & - & - & 50 & - & 20 & - & 35 & 63 & - & - \\
\hline Growth stage $\times$ abiotic stress $\times$ Genotypes & 0.23 & 0.26 & 0.05 & 0.32 & 0.25 & 0.19 & 0.05 & 0.12 & 0.05 & 0.046 & 0.05 & 0.011 & 0.033 & 0.001 \\
\hline PSPD & & & 10 & & & - & 10 & & 10 & 35 & 28 & 60 & 25 & 79 \\
\hline Stress phase $\times$ Abiotic stress $\times$ Genotypes & 0.15 & 0.35 & 0.05 & 0.02 & 0.04 & 0.02 & 0.03 & 0.22 & 0.37 & 0.03 & 0.05 & 0.05 & 0.02 & 0.008 \\
\hline PSPD & - & - & 8 & 62 & 53 & 50 & 62 & - & - & 52 & 17 & 30 & 30 & 67 \\
\hline Stress phase $\times$ Growth stage $\times$ Genotypes & 0.55 & 0.89 & 0.05 & 0.19 & 0.34 & 0.62 & 0.50 & 0.31 & 0.25 & 0.011 & 0.05 & 0.047 & 0.05 & 0.029 \\
\hline \multirow[t]{2}{*}{ PSPD } & - & - & 25 & - & - & - & - & - & - & 79 & 30 & 43 & 43 & 50 \\
\hline & \multicolumn{14}{|c|}{ Summary statistics of Generalized Linear Model Fit } \\
\hline Mean of Response (PPs) & 0.68 & 0.64 & 0.86 & 0.88 & 0.86 & 0.59 & 0.82 & 0.75 & 0.78 & 0.67 & 0.79 & 0.66 & 0.75 & 0.72 \\
\hline & 0.045 & 0.046 & 0.022 & 0.015 & 0.006 & 0.022 & 0.013 & 0.022 & 0.035 & 0.035 & 0.037 & 0.044 & 0.047 & 0.054 \\
\hline \multirow[t]{2}{*}{ Adjusted $R^{2}$} & 0.75 & 0.82 & 0.80 & 0.95 & 0.95 & 0.93 & 0.98 & 0.79 & 0.80 & 0.92 & 0.76 & 0.87 & 0.82 & 0.69 \\
\hline & \multicolumn{14}{|c|}{ Percent change in phenotypic plasticity estimates due to abiotic stress (mean \pm 95\% confidence intervals; difference between SH in 2011 and NN in 2006) } \\
\hline \multirow{3}{*}{$\begin{array}{l}\text { T. aestivum } \\
\text { T. durum }\end{array}$} & $-36.5(12.8)$ & $-22.3(7.7)$ & $-27.3(5.6)$ & $-32.0(9.5)$ & $-25.5(5.0)$ & $-12.8(3.8)$ & $-15.3(2.8)$ & $3.8(1.9)$ & $4.2(2.0)$ & $5.4(0.9)$ & $6.2(1.8)$ & $8.1(2.8)$ & $5.9(1.4)$ & $6.6(1.5)$ \\
\hline & $-40.2(9.2)$ & $-32.8(6.5)$ & $-29.6(7.2)$ & $-38.3(9.0)$ & $-37.2(7.8)$ & $-15.2(1.6)$ & $-13.8(3.1)$ & $4.6(1.8)$ & $3.4(1.5)$ & $5.0(1.1)$ & $6.2(2.0)$ & $7.5(2.2)$ & $5.5(1.4)$ & $6.2(1.7)$ \\
\hline & \multicolumn{14}{|c|}{ Phenotypic Coefficients of Variation (PCV, \%) (2006-2011) } \\
\hline T. aestivum & 22.9 & 28.8 & 29.9 & 28.6 & 8.9 & 6.3 & 5.2 & 16.8 & 3.4 & 15.2 & 17.9 & 10.5 & 8.3 & 12.5 \\
\hline
\end{tabular}


Table 2. Cont

\begin{tabular}{|c|c|c|c|c|c|c|c|c|c|c|c|c|c|c|}
\hline \multirow{2}{*}{$\begin{array}{c}\text { Covariates } \\
\text { T. durum }\end{array}$} & \multicolumn{8}{|c|}{ Plasticity of Agronomic Traits } & \multicolumn{6}{|c|}{ Plasticity of C:N and Micronutrients \& Their Index, MNI } \\
\hline & 18.6 & 28.0 & 27.5 & 29.5 & 9.5 & 6.5 & 5.0 & 15.3 & 3.0 & 18.6 & 19.0 & 12.5 & 9.5 & 13.5 \\
\hline & \multicolumn{14}{|c|}{ Genotypic Coefficients of Variation (GCV, \%) (2006-2011) } \\
\hline T. aestivum & 23.3 & 24.6 & 25.6 & 25.4 & 7.2 & 5.6 & 4.9 & 15.0 & 3.0 & 13.8 & 14.9 & 8.3 & 7.9 & 10.8 \\
\hline \multirow[t]{2}{*}{ T. durum } & 24.6 & 23.3 & 25.3 & 25.0 & 8.3 & 5.9 & 4.9 & 14.2 & 3.0 & 17.5 & 12.3 & 9.5 & 8.8 & 11.2 \\
\hline & \multicolumn{14}{|c|}{ Narrow-sense heritability $\left(h^{2}\right)(\%)$} \\
\hline T. aestivum & 67.5 & 64.3 & 62.3 & 59.8 & 75.3 & 88.9 & 80.5 & 56.9 & 89.3 & 38.9 & 34.6 & 48.9 & 52.8 & 43.2 \\
\hline T. durum & 69.2 & 65.3 & 65.5 & 56.8 & 77.6 & 87.0 & 87.2 & 58.2 & 88.6 & 40.2 & 35.8 & 46.3 & 50.7 & 42.5 \\
\hline
\end{tabular}


Almost equal portions (60\%) of test statistics for PPs in agronomic and micronutrient traits due to single fixed factors were significant. Most of the significant effects were mediated by differences between wheat genotypes and between stress phases; while kernels $\mathrm{m}^{-2}$ and grain protein content exhibited significant differences due to all single fixed factors. Micronutrients (and their index, but not $\mathrm{C}: \mathrm{N}$ ratio) displayed significant differences due to single fixed factors; with a few exceptions (e.g., Fe, $\mathrm{Mn}$, and micronutrients index due to stress phases and abiotic stress treatments). Two-way interactions significantly affected $91 \%$ of agronomic traits PPs. Different reactions of wheat genotypes to abiotic stress resulted in significant differences for all agronomic traits, followed by their interaction with stress phases and with growth stages. Significant differences due to interaction of growth stage with abiotic stresses were limited to biomass, population density, kernel weight, and grain protein content. Almost all PPs for the micronutrients index and micronutrients index, as well as C:N ratio, displayed significant differences due to two-way interactions; the only exceptions were $\mathrm{Fe}$ and $\mathrm{Zn}$ in response to growth stage $\times$ abiotic stress. Three-way interactions were less effective in significantly affecting all PPs (34\%); however, larger portion of agronomic trait PPs (71\%) when compared to a smaller portion of C:N were not significantly affected by these interactions; while all PPs for the micronutrients index were significantly affected by all three-way interactions.

Summary statistics of the GLM analysis indicated that the mean of response (i.e., estimated PPs) ranged from a minimum of 0.59 (spike harvest index) to a maximum of 0.88 (grain yield). However, the model accounted for a minimum of 0.69 (micronutrients index) to a maximum of 0.98 (kernels $\mathrm{m}^{-2}$ ) of variation (adjusted $R^{2}$ ) in PPs of all traits; the majority of which were $>0.80$. Percent change in PPs of both wheat genotypes due to maximum abiotic stress (SH during SPII) when compared with their estimates due to NN during SP I were larger for agronomic traits as compared to micronutrients index; while, both genotypes displayed similar trends with a few exceptions. Triticum durum experienced slightly more reductions than T. aestivum in most agronomic trait PPs $(-15.2 \pm 1.6$ for spike harvest index to $-40.2 \pm 9.2$ for biomass); while, the slight increases in nutrients and C:N ratio were comparable. Four agronomic traits (BM, PD, FT, and GY) had larger PCV and GCV values (18.6 to 29.9) for PPs than those for micronutrients index (8.3 to 18.6). Most PCV estimates were larger than their GCV counterparts, while no clear trend can be detected between both wheat genotypes. Narrow-sense heritability estimates $\left(h^{2}\right)$ were larger for agronomic traits (56.8\% to $88.9 \%$ ) than for micronutrients and their index (34.6\% to 52.8\%) PPs; while, the largest estimates were those for C:N in both genotypes.

Five-way cluster analyses of PPs in two wheat genotypes (T. durum and T. aestivum), and discriminant analysis (i.e., percent correct classification) of two stress phases (SP I and SP II), two growth stages (reproductive, and full maturity), and three levels of abiotic stress ( $\mathrm{NH}, \mathrm{SN}, \mathrm{SH}$ ) as compared to a no-stress control (NN) are presented in Figure 2. Similarities and differences between the two wheat genotypes can be deduced from the multi-way, multi-variate clustering and discriminant analyses of PPs for agronomic traits, in addition to the micronutrients index and C:N ratio. The PPs legend indicated similar ranges for both wheat genotypes. However, PPs clustered with slightly different configurations in each genotype. Two main clusters in T. aestivum were composed of biomass-population density-kernels $\mathrm{m}^{-2}$-micronutrients index, and fertile tillers-grain yield-spike fertility index-C:N, with spike harvest index in between; the two corresponding clusters in T. durum were composed of biomass-spike harvest index-population density-C:N, and fertile tillers-spike fertility index-grain yield-kernels $\mathrm{m}^{-2}$, with $\mathrm{C}: \mathrm{N}$ and micronutrient index in between. Numerous combinations of two, or more small, medium, and large PPs can be visualized in these clusters. A few PPs were uniform in T. aestivum (e.g., spike harvest index at the lower scale, and spike fertility index at the intermediate scale) and in T. durum (e.g., population density at the lower scale and both kernels $\mathrm{m}^{-2}$ and grain yield at the largest scale). Discrimination between levels of three factors, superimposed upon these clusters, suggested that differences between both genotypes whether considering one, two, or all three factors were large. Percent correct classification of these factors decreased in the same order in both genotypes. Stress phases were $87 \%$ and $72 \%$ correctly classified in T. aestivum, and $97 \%$ and $96 \%$ 
in T. durum. Percent correct classification of reproductive phase in T. aestivum (65\%) and T. durum (71\%) were smaller than the respective values for full maturity (89\% and $87 \%$ ) growth stages. The smallest correct classifications were those of abiotic stresses; the largest in both genotypes was NN (50\% and $61 \%$ ), followed, in decreasing order by $\mathrm{NH}$ and $\mathrm{SH}$ (39\% each), then by SN (28\%) in T. aestivum, and by $\mathrm{SN}(55 \%)$, NH $(32 \%)$, and SH (26\%) in T. durum.
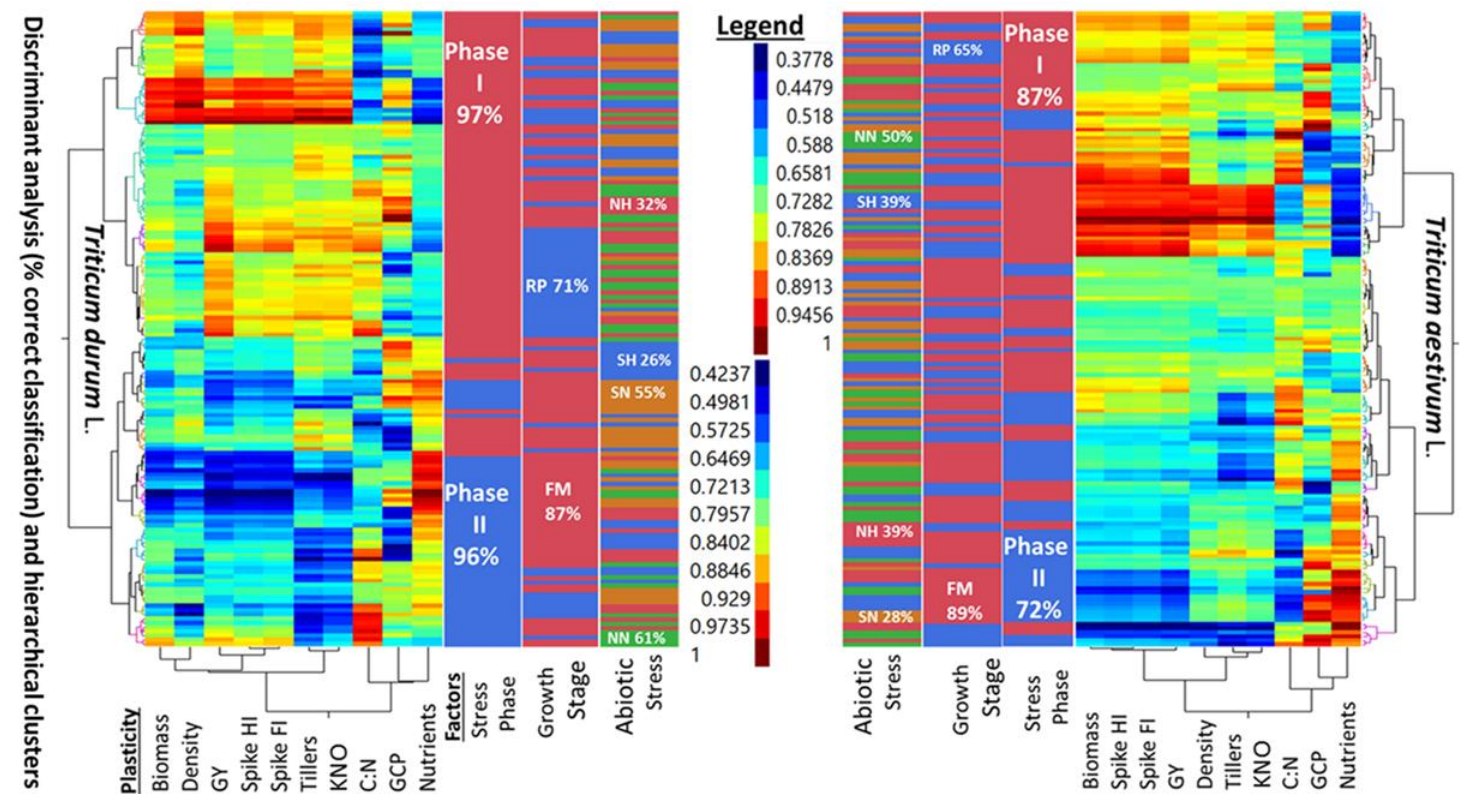

\section{Factors and Variables}

Figure 2. Multi-way cluster analyses for two wheat genotypes, representing T. durum and T. aestivum, of phenotypic plasticity estimates on agronomic traits and micronutrients index, and discriminant analysis (i.e., percent correct classification) of two stress phases (SP I and SP II), two growth stages (reproductive stage, RP and full maturity, FM), and three levels of abiotic stress (NH, normal length of growing season, $\mathrm{SN}$, short growing season and normal population density, and $\mathrm{SH}$, short growing season and high population density) compared to a control (NN, normal length of growing season and normal population density).

Results of the graphical discriminant analysis, quantitative description of bivariate distributions (95\% ellipsis), and associations between PPs of agronomic and micronutrient traits in T. durum (red) and T. aestivum (green) subjected to abiotic stress are presented in Figure 3. The 95\% joint ellipses suggested that the PPs were largely (67\%) uncoupled; while, the remaining 33\% were either totally or almost totally overlapping. Most uncoupled distributions have PPs of kernels $\mathrm{m}^{-2}$, spike harvest index, spike fertility index and grain yield involved in bivariate associations with other traits. Most bivariate associations, where the $95 \%$ confidence ellipsis of both wheat genotypes overlapped, included PPs of grain protein content with each of BD, population density, PT, C:N, and nutrients index. In these, and some other bivariate distributions, the $95 \%$ confidence ellipsis of T. durum was encompassing those of T. aestivum. Positive and negative bivariate associations between PPs comprised 33.3 and $20.0 \%$ of all bivariate associations, respectively. 


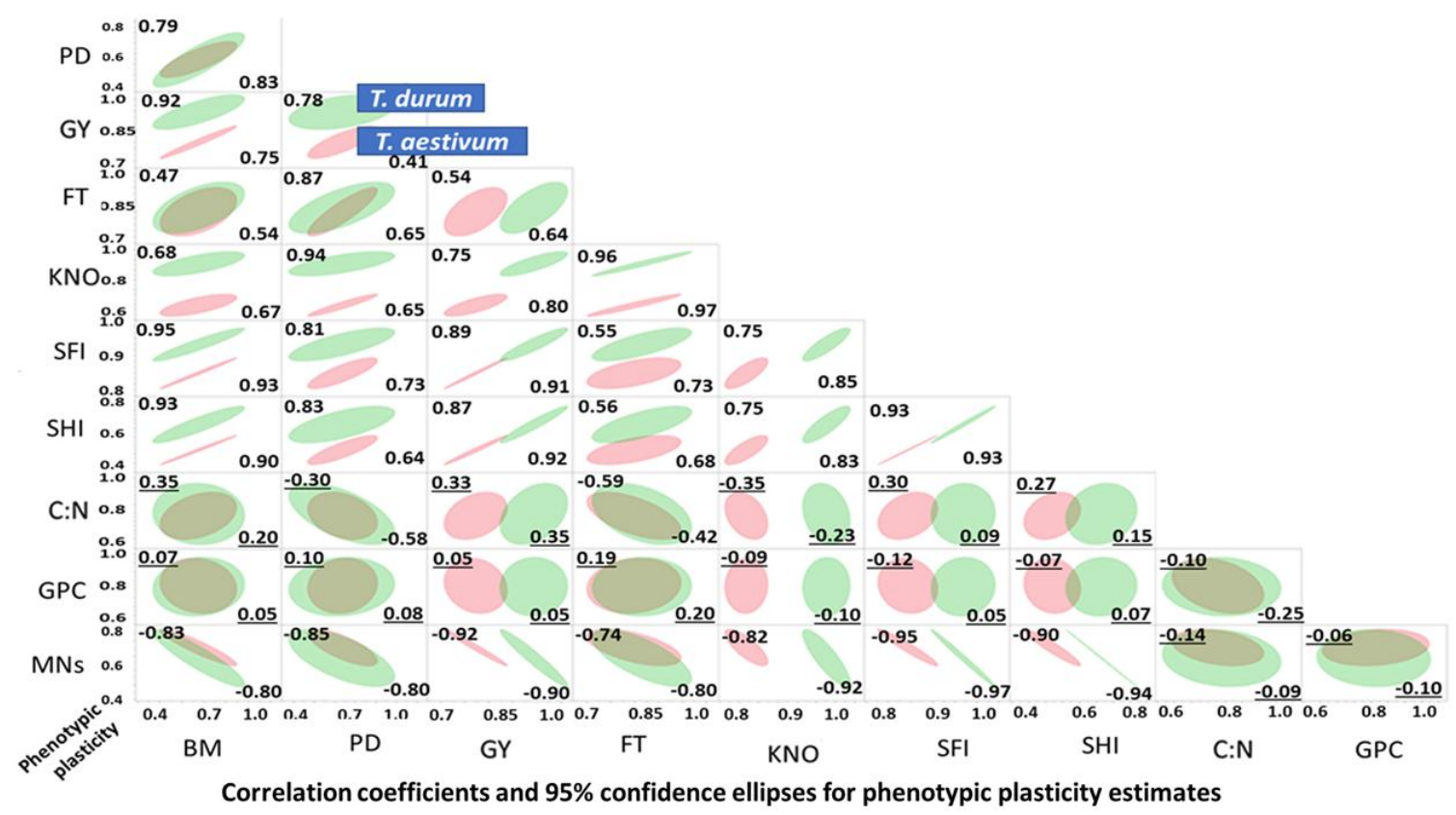

Figure 3. Bivariate correlation coefficients, graphical discriminant analysis and semi-quantitative description of bivariate distributions and associations (95\% ellipsis) between phenotypic plasticity estimates of agronomic and micronutrient traits in T. durum genotype (red) and T. aestivum genotype (green) subjected to abiotic stress.

Bivariate relationships between trait PPs ranged from 0.0 to $>0.90$, with a few being negative but not significant. Most negative correlations involved C:N, grain protein content and nutrient PP estimates. Close to half $(47.0 \%)$ of all correlation coefficients for T. durum and T. aestivum were positive and significant; $18 \%$ and $22 \%$ were positive but not significant, respectively; $18 \%$ and $20 \%$ were negative and significant, respectively; and, the remaining $17 \%$ and $11 \%$ were negative, but not significant, respectively.

\subsection{Ontogeny's Impact on PPs}

Box-plots and mean separation between PPs of grain yield (Figure 4) indicated some similarities at the large scale, but many differences when different levels of abiotic stress (i.e., abiotic stress treatments: $\mathrm{NH}, \mathrm{NN}, \mathrm{SH}$, and $\mathrm{SN}$ ) were considered. When one or both stress phases were considered, PPs for grain yield were significantly larger in T. durum than T. aestivum; the same trend was observed at growth stages within the stress phases. However, within each wheat genotype, levels of significant differences between abiotic stress treatments at each maturity stage presented variable statistics and significant differences followed, to some extent, the trend of the $95 \%$ confidence intervals around the mean in each case. During the reproductive phase, significant differences were found in T. aestivum during $\mathrm{SP}$ I between $\mathrm{SN}$ and $\mathrm{SH}$, on one hand, and $\mathrm{NN}$ and $\mathrm{NH}$, on the other; these differences, however, disappeared at full maturity; whereas, the larger significant differences between PPs of abiotic stress treatment at the reproductive phase during PS II persisted at full maturity, with SN and SH being significantly larger than NH and NN. During SP I and SP II, significant differences between abiotic stress treatments persisted during both of the growth stages in T. durum. However, PPs for grain yield due to short growing season with normal or high population densities (SN and $\mathrm{SH}$, respectively), unlike T. aestivum, were significantly smaller than those attributed to $\mathrm{NN}$ and $\mathrm{NH}$.

Most micronutrients index PPs in T. durum were larger than their counterparts in T. aestivum, with significant differences at SP II and at both growth stages (Figure 5). Abiotic stress levels at the reproductive phase within SP I were more variable in T. durum than their counterparts in T. aestivum, 
especially for $\mathrm{NN}$ and $\mathrm{NH}$. This large variability persisted in $\mathrm{NN}$ for T. aestivum at full maturity during both stress phases, and for T. durum at full maturity during SP II.

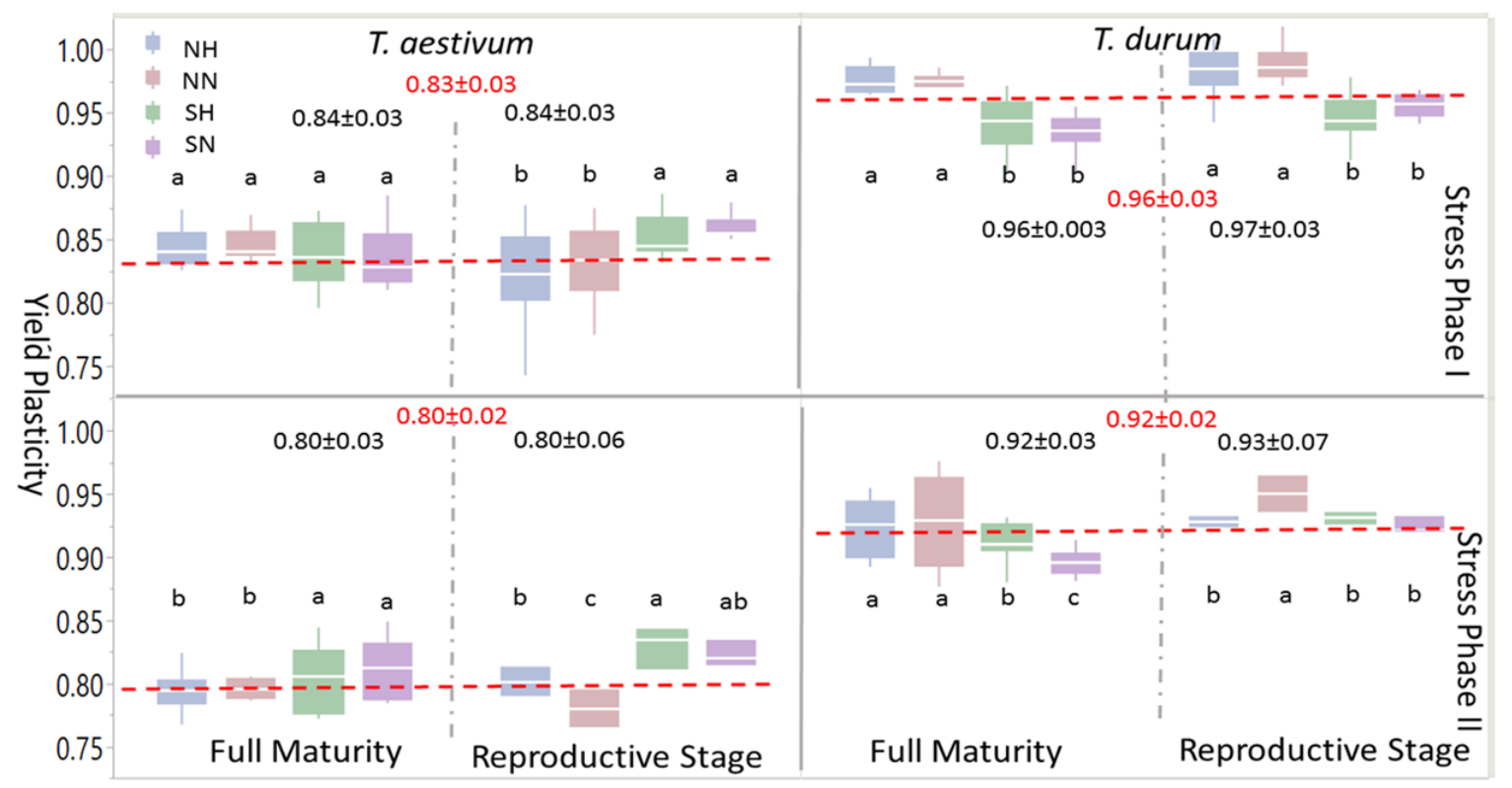

Growth stage

Figure 4. Box-plots and mean separation (means followed by the same letter within each growth stage do not differ significantly using Tukey's HSD; $p=0.05$ ) of grain yield phenotypic plasticity estimates for two wheat genotypes representing T. durum and T. aestivum subjected to three levels of abiotic stresses ( $\mathrm{NH}$, normal length of growing season and high population density, $\mathrm{SN}$, short growing season and normal population density, and $\mathrm{SH}$, short growing season and high population density) and compared to a control (NN, normal length of growing season and normal population density) during reproductive and full maturity growth stages.

Significant differences between abiotic stress treatments in T. durum were minimal at full maturity under SP I and maximal under SP II. Respective cases for T. aestivum were during the reproductive phase and full maturity during SP I. Comparisons between population density at the same level of length of growing season, or alternatively between length of growing season at the same population level provided insights into interactions between these levels at the same or at different growth stages in one or both wheat genotypes. For example, estimates of extreme abiotic stress (i.e., SH) differed significantly from the control (i.e., NN), except at the reproductive phase of T. aestivum during SP II; while, $\mathrm{NH}$ and $\mathrm{SH}$, for example, expressed significant differences for all comparisons, except at the reproductive phase during SP II in T. durum. 


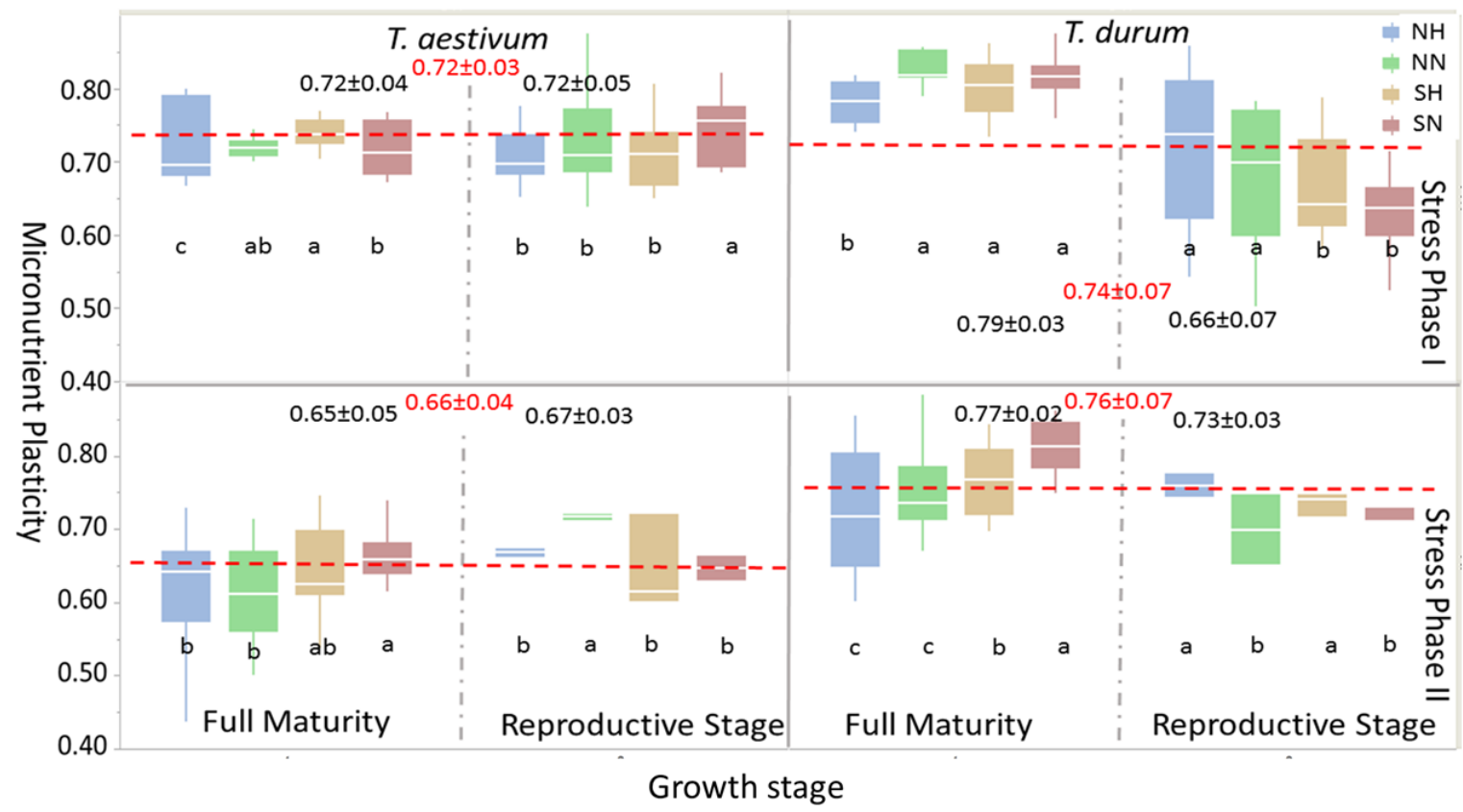

Figure 5. Box-plots and mean separation (means followed by the same letter within each growth stage do not differ significantly using Tukey's HSD; $p<0.05$ ) of micronutrients index phenotypic plasticity estimates for two wheat genotypes representing T. durum and T. aestivum subjected to three levels of abiotic stresses ( $\mathrm{NH}$, normal length of growing season, $\mathrm{SN}$, short growing season and normal population density, and $\mathrm{SH}$, short growing season and high population density) and compared to a control (NN, normal length of growing season and normal population density) during reproductive and full maturity growth stages.

\subsection{Modeling Phenotypic Plasticity}

\subsubsection{Wheat Genotypes}

Results of the partial least squares regression (PLSR), factor analyses, prediction of micronutrients as functions of PPs, multivariate distances, and matrix correlations between predictors and between the predicted variables for T. aestivum and T. durum under two abiotic stress phases are presented in Table 3 . In T. aestivum, the PLSR1 component of the calibration model extracted a wide range of variation $\left(R^{2} X\right.$ PLSR1: 0.08 to $>0.80)$ in dependent variables and accounted for 0.57 of validation variance $\left(Q^{2} Y\right)$. Comparable values were obtained for T. durum; however, with a slightly larger $Q^{2} Y(0.63)$. Loadings of nine predictors on two independent factors explained 0.94 and 0.92 of total variation in T. aestivum and T. durum, respectively. Loadings on each Factor of a varimax rotated matrix of these variables identified some differences between wheat genotypes, especially for population density, fertile tillers, kernels $\mathrm{m}^{-2}$, and C:N ratio. Most PLSR model coefficients for centered and scaled data were negative; however, those for grain protein content were the exception in their magnitude and positive effect. The matrix correlation coefficient between predictor variables of T. aestivum and T. durum was smaller (0.53) and not significant $(z=0.21)$ when compared with the larger (0.65), and significant $(z=0.05)$ one between nutrient matrices. In addition, PLSR1 accounted for comparable $R^{2} Y$ variances in Fe and Zn, but different variances in $\mathrm{Cu}$ and $\mathrm{Mn}$ when wheat genotypes were considered. The $\mathrm{C}: \mathrm{N}$ ratio, besides its negative effects on most micronutrients in both genotypes, exhibited different, but mostly negative and significant relationships with PPs of these micronutrients, with a clear difference between the wheat genotypes for Mn.

Functional relationships, as quantified by the RMA slope ( \pm s.e.) between micronutrients in both wheat genotypes ranged from $0.55 \pm 0.04$ for $\mathrm{Mn}$, to $1.10 \pm 0.04$ for $\mathrm{Cu}$, which was the only value significantly above 1.0 and a large Jackknifed $R^{2}$ of $0.74 \pm 0.03$. The multivariate distance between 
both wheat genotypes $\left(D^{2}=451.8\right)$ was significant $(p<0.0001)$ and it was supported by the significant F-value for univariate test between genotypes (0.01) and the F-value for multivariate tests between independent variables (0.04), which, when combined, accounted for 0.46 of the total variation.

Table 3. Multiple comparisons between wheat genotypes representing T. aestivum and T. durum wheat species using partial least squares regression (PLSR), factor analyses, prediction of micronutrients as functions of phenotypic plasticities, multivariate distances, and matrix correlations between predictors and between predicted variables.

\begin{tabular}{|c|c|c|c|c|c|c|c|c|c|}
\hline \multirow{3}{*}{ Factor } & \multirow{3}{*}{ Sub-Factors } & \multirow{3}{*}{ Predictors } & \multirow{3}{*}{$R^{2} X$ PLSR1 } & \multicolumn{2}{|c|}{ Varimax Rotated Loadings } & \multirow{2}{*}{\multicolumn{4}{|c|}{$\begin{array}{c}\text { PLSR Model Coefficients for Centered and Scaled Data } \\
\text { Dependent Variables }\end{array}$}} \\
\hline & & & & \multirow{2}{*}{ Factor 1} & \multirow{2}{*}{ Factor 2} & & & & \\
\hline & & & & & & $\mathrm{Cu}$ & $\mathrm{Fe}$ & Mn & $\mathrm{Zn}$ \\
\hline \multirow[t]{26}{*}{ Genotypes } & T. aestivum & $\mathrm{BM}$ & 0.97 & 0.92 & & -0.044 & -0.22 & -0.075 & -0.218 \\
\hline & & PD & 0.84 & 0.70 & 0.67 & -0.075 & -0.068 & -0.075 & -0.074 \\
\hline & & FT & 0.41 & 0.41 & 0.89 & -0.085 & 0.058 & -0.062 & 0.063 \\
\hline & & GY & 0.98 & 0.93 & & -0.052 & -0.202 & -0.078 & -0.199 \\
\hline & & SFI & 0.94 & 0.87 & & -0.051 & -0.020 & -0.070 & -0.202 \\
\hline & & SHI & 0.96 & 0.82 & & -0.050 & -0.020 & -0.078 & -0.200 \\
\hline & & KNO & 0.65 & 0.64 & 0.75 & -0.084 & -0.021 & -0.074 & -0.029 \\
\hline & & GPC & 0.53 & -0.51 & & 0.125 & 0.154 & 0.114 & 0.098 \\
\hline & & C:N & 0.08 & 0.44 & -0.88 & 0.043 & -0.241 & -0.004 & -0.226 \\
\hline & Factor $\mathrm{v}$ & ariance & & 0.64 & 0.30 & & & & \\
\hline & $R^{2} Y$ & 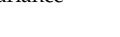 & & & & 0.18 & 0.82 & 0.21 & 0.80 \\
\hline & $Q^{2} Y$ & & 0.57 & & & & & & \\
\hline & $r-\mathrm{C}: \mathrm{N}$ & & & & & -0.05 & $-0.48^{* \dagger}$ & 0.11 & $-0.52 *$ \\
\hline & T. durum & BM & 0.80 & 0.88 & & -0.015 & -0.295 & -0.356 & -0.230 \\
\hline & & PD & 0.55 & 0.62 & -0.69 & -0.075 & -0.130 & -0.122 & -0.125 \\
\hline & & FT & 0.64 & 0.71 & -0.45 & -0.325 & 0.082 & 0.243 & -0.025 \\
\hline & & GY & 0.83 & 0.96 & & -0.107 & -0.200 & -0.189 & -0.189 \\
\hline & & SFI & 0.95 & 0.92 & & -0.094 & -0.222 & -0.220 & -0.202 \\
\hline & & SHI & 0.90 & 0.89 & & -0.084 & -0.235 & -0.241 & -0.209 \\
\hline & & KNO & 0.79 & 0.85 & -0.38 & -0.279 & -0.005 & 0.121 & -0.080 \\
\hline & & GPC & 0.49 & -0.42 & & 0.058 & 0.214 & 0.220 & 0.198 \\
\hline & & $\mathrm{C}: \mathrm{N}$ & 0.01 & & 0.98 & 0.175 & -0.207 & -0.324 & -0.116 \\
\hline & Factor v & ariance & & 0.67 & 0.25 & & & & \\
\hline & $R^{2} Y$ & & & & & 0.75 & 0.85 & 0.50 & 0.90 \\
\hline & $Q^{2} Y$ & & 0.63 & & & & & & \\
\hline & $r-\mathrm{C}: \mathrm{N}$ & & & & & 0.15 & $-0.22 *$ & -0.30 * & $-0.21 *$ \\
\hline Probability > F & 0.01 & 0.04 & & & & & & & \\
\hline $\begin{array}{l}R^{2} \\
\text { RMA Slope (se) }\end{array}$ & \multicolumn{2}{|c|}{0.46} & & & & & & & \\
\hline Jackknife $R^{2}$ (s.e.) & & & & & & $\begin{array}{l}1.10(0.04) \\
0.74(0.03)\end{array}$ & $\begin{array}{l}0.64(0.05) \\
0.13(0.06)\end{array}$ & $\begin{array}{l}0.55(0.04) \\
0.09(0.02)\end{array}$ & $0.36(0.06)$ \\
\hline \multicolumn{10}{|c|}{ Multivariate test statistics } \\
\hline Predictor matrix $r$ & \multicolumn{2}{|c|}{$0.53 ; z=0.21$} & & & & & & & \\
\hline Nutrient matrix $r$ & \multirow{2}{*}{\multicolumn{2}{|c|}{$\begin{array}{c}0.65 ; z=0.05 \\
451.8 ; p<0.0001\end{array}$}} & & & & & & & \\
\hline Mahalanobis $D^{2}$ & & & & & & & & & \\
\hline
\end{tabular}

\subsubsection{Stress Phases}

Results of PLSR, Factor Analyses, prediction of micronutrients as functions of PPs, multivariate distances, and matrix correlations between predictors and between predicted variables for two stress phases (PS I ad PS II) are presented $\mathrm{n}$ Table 4. At the calibration model stage, PLSR1 extracted small (0.07 and 0.02) to large (0.90 and 0.84$)$ portions of variation in individual predictors, explained large portions of variation $\left(R^{2} Y\right)$ in all micronutrients, except for $\mathrm{Cu}$, and accounted for similar validation variances $\left(Q^{2} Y\right)$ under PS I (0.74) and PS II (0.74). Coefficients of the PLSR model for centered and scaled data were mostly negative $(83.3 \%)$, except those for spike fertility index $(\mathrm{Cu})$, kernels $^{-2}(\mathrm{Cu}$ and $\mathrm{Fe})$, and grain protein content $(\mathrm{Cu}, \mathrm{Fe}$, and $\mathrm{Zn})$ during SP I; while, 38.9\% of those coefficients were positive during PS II. Coefficients of biomass and C:N were generally larger in magnitude than most others for both of the stress phases. The rotated varimax loadings of two factors composed of independent variables explained 0.86 and 0.76 of total variation under SP I and SP II, respectively; these loadings differed in magnitude between the stress phases, especially for population density, fertile tillers, grain protein content, and C:N. Large differences were found between SP I ( -0.06 to -0.22$)$ and SP II ( -0.81 to 0.42$)$ in the magnitude and significance of C:N correlations with micronutrients.

Functional relationships between micronutrients under both stress phases were larger than 1.0, except $\mathrm{Cu}$; however, the Jackknifed $R^{2}$ estimates were uniformly small (0.13-0.18). Overall, differences 
between SP I and SP II $(p<0.01)$ and between predictors $(p<0.05)$ were significant; while, the whole model accounted for only 0.44 of total variation. Predictor matrices were not significantly correlated $(r=0.57 ; z=0.18)$; while, micronutrients matrices were significantly correlated $(r=0.83 ; z<0.01)$ and the multivariate distance $\left(D^{2}=68.9 ; p<0.001\right)$ separating both stress phases was significant.

Table 4. Multiple comparisons between two abiotic stress phases imposed on T. aestivum and T. durum, each of three years, using partial least squares regression (PLSR), factor analyses, prediction of micronutrients as functions of phenotypic plasticities, multivariate distances, and matrix correlations between predictors and between predicted variables.

\begin{tabular}{|c|c|c|c|c|c|c|c|c|c|}
\hline \multirow{3}{*}{ Factor } & \multirow{3}{*}{ Sub-Factors } & \multirow{3}{*}{ Predictors } & \multirow{3}{*}{$R^{2} X$ PLSR1 } & \multicolumn{2}{|c|}{ Varimax Rotated Loadings } & \multirow{2}{*}{\multicolumn{4}{|c|}{$\begin{array}{c}\text { PLSR Model Coefficients for Centered and Scaled Data } \\
\text { Dependent Variables }\end{array}$}} \\
\hline & & & & \multirow{2}{*}{ Factor 1} & \multirow{2}{*}{ Factor 2} & & & & \\
\hline & & & & & & $\mathrm{Cu}$ & $\mathrm{Fe}$ & Mn & $\mathrm{Zn}$ \\
\hline \multirow[t]{26}{*}{ Stress Phase } & Phase I & BM & 0.40 & & 0.76 & -0.205 & -0.450 & -0.210 & -0.486 \\
\hline & & PD & 0.38 & & 0.96 & -0.045 & -0.177 & -0.135 & -0.179 \\
\hline & & FT & 0.65 & 0.54 & 0.70 & -0.008 & -0.134 & -0.143 & -0.128 \\
\hline & & GY & 0.83 & 0.90 & & -0.003 & -0.160 & -0.182 & -0.152 \\
\hline & & SFI & 0.90 & 0.85 & & 0.013 & -0.143 & -0.184 & -0.130 \\
\hline & & SHI & 0.92 & 0.79 & & -0.011 & -0.184 & -0.195 & -0.175 \\
\hline & & KNO & 0.75 & 0.92 & & 0.089 & 0.001 & -0.134 & -0.028 \\
\hline & & GPC & 0.62 & 0.27 & & 0.053 & 0.162 & -0.019 & 0.116 \\
\hline & & C:N & 0.07 & & -0.74 & -0.227 & -0.348 & -0.059 & -0.396 \\
\hline & Factor $\mathrm{v}$ & ariance & & 0.53 & 0.33 & & & & \\
\hline & $R^{2} Y$ & & & & & 0.01 & 0.80 & 0.92 & 0.69 \\
\hline & $Q^{2} Y$ & & 0.74 & & & & & & \\
\hline & $r-\mathrm{C}: \mathrm{N}$ & & & & & -0.13 & -0.06 & 0.12 & -0.22 *t \\
\hline & Phase II & BM & 0.39 & & 0.65 & 0.198 & -0.478 & -0.313 & -0.401 \\
\hline & & PD & 0.02 & & & 0.096 & -0.228 & -0.110 & -0.169 \\
\hline & & FT & 0.30 & & -0.86 & -0.063 & 0.153 & 0.129 & 0.145 \\
\hline & & GY & 0.76 & 0.96 & & 0.032 & -0.085 & -0.140 & -0.121 \\
\hline & & SFI & 0.75 & 0.89 & & 0.034 & -0.089 & -0.142 & -0.124 \\
\hline & & SHI & 0.84 & 0.87 & & 0.054 & -0.137 & -0.171 & -0.162 \\
\hline & & $\mathrm{KNO}$ & 0.41 & 0.97 & & -0.039 & 0.086 & -0.029 & 0.022 \\
\hline & & GPC & 0.44 & -0.33 & & 0.089 & 0.095 & 0.013 & 0.102 \\
\hline & & $\mathrm{C}: \mathrm{N}$ & 0.05 & & 0.92 & 0.128 & -0.311 & -0.244 & -0.285 \\
\hline & Factor $\mathrm{v}$ & ariance & & 0.48 & 0.28 & & & & \\
\hline & $R^{2} Y$ & & & & & 0.11 & 0.70 & 0.79 & 0.80 \\
\hline & $Q^{2} Y$ & & 0.72 & & & & & & \\
\hline & $r-\mathrm{C}: \mathrm{N}$ & & & & & $0.42 *$ & $-0.79 *$ & $-0.65^{*}$ & $-0.81 *$ \\
\hline Probability $>F$ & 0.01 & 0.05 & & & & & & & \\
\hline$R^{2}$ & 0. & & & & & & & & \\
\hline RMA Slope (s.e.) & & & & & & $0.87(0.08)$ & $1.28(0.11)$ & $1.51(0.13)$ & $1.51(0.13)$ \\
\hline Jackknife $R^{2}$ (s.e.) & & & & & & $0.18(0.04)$ & $0.17(0.02)$ & $0.16(0.02)$ & $0.13(0.03)$ \\
\hline \multicolumn{10}{|c|}{ Multivariate test statistics } \\
\hline Predictor matrix $r$ & $0.57 ; z$ & $=0.18$ & & & & & & & \\
\hline Nutrient matrix $r$ & $0.83 ; z$ & 0.01 & & & & & & & \\
\hline Mahalanobis $D^{2}$ & $68.9 ; p$ & 0.001 & & & & & & & \\
\hline
\end{tabular}

\subsubsection{Growth Stages}

Multiple comparisons between T. aestivum and T. durum at the reproductive phase (anthesis + 15 days) and full maturity growth stages, while using multivariate statistical analyses procedures identified similarities and a few differences between these growth stages (Table 5). The PLSR calibration model, with the exception of the C:N ratio, extracted large and almost uniform amounts of variation ( 0.36 for PT to 0.90 for spike fertility index in reproductive phase, and 0.24 for population density to 0.86 for spike harvest index in full maturity) and accounted for 0.70 and 0.68 of validation variances in reproductive phase and full maturity, respectively. On the other hand, the variance portion in micronutrients explained by the model was extremely small for $\mathrm{Cu}$, while it was large $(>0.65)$ for other micronutrients.

The majority of PLSR model coefficients for the reproductive phase $(75.0 \%)$ and full maturity $(80.6 \%)$ were negative, with clear differences between most $\mathrm{Cu}$-coefficients between growth stages. Model coefficients for centered and scaled data, especially those for grain protein content, displayed some differences between growth stages. At full maturity, larger (more negative) coefficients were observed for biomass; while, those of grain protein content were positive and larger than their counterparts at the reproductive phase. 
Table 5. Multiple comparisons between reproductive (anthesis +15 days) and full maturity growth stages of T. aestivum and T. durum, each of three years, using partial least squares regression (PLSR), factor analyses, prediction of micronutrients as functions of phenotypic plasticities, multivariate distances, and matrix correlations between predictors and between predicted variables.

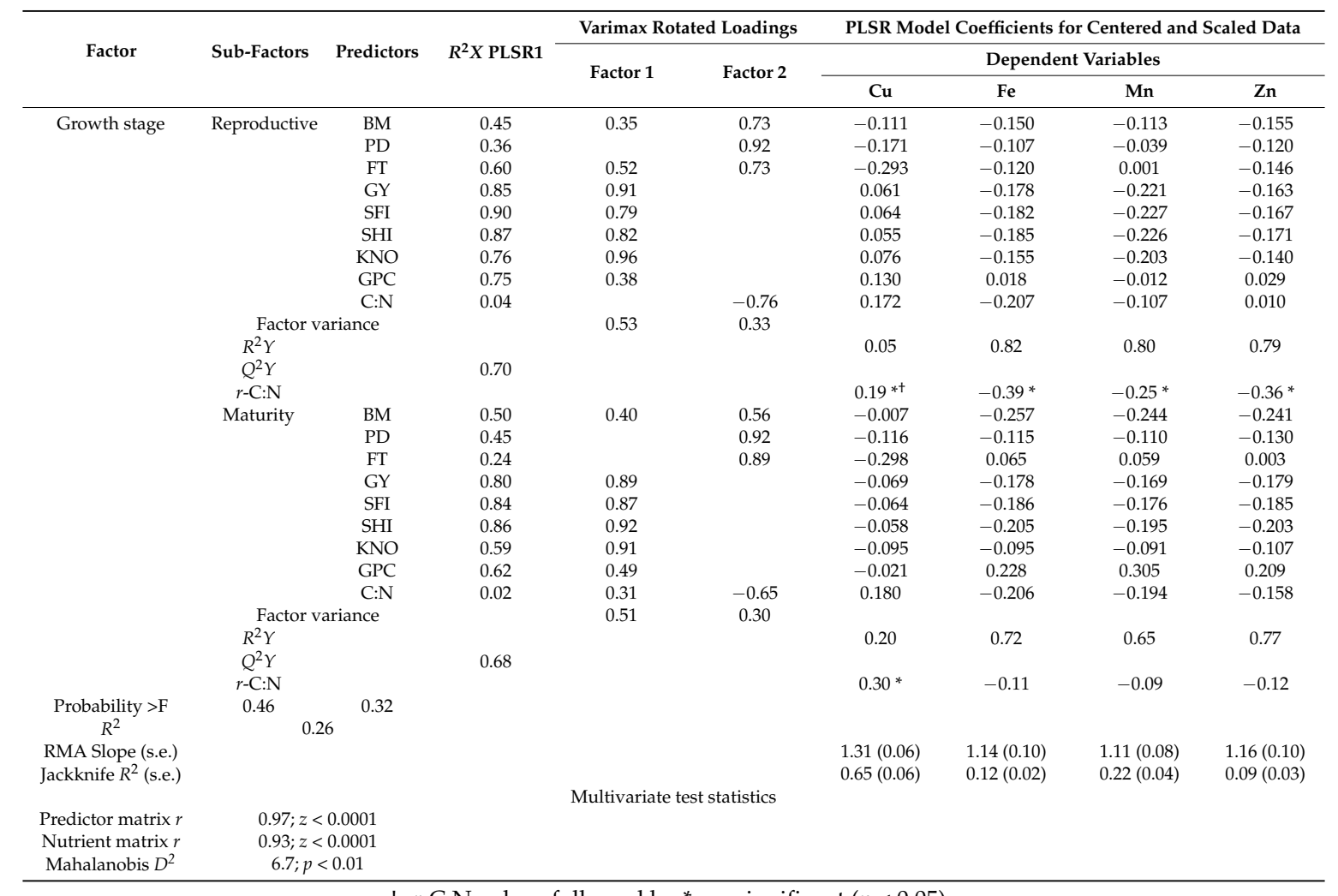

,$+ r$-C:N values followed by * are significant $(p<0.05)$.

The structure, loadings, and amount of variation explained by two independent Factors for reproductive phase and full maturity growth stages were remarkably similar, except for a positive loading of C:N on full maturity-Factor 1. Total variation explained by both factors was 0.83 and 0.81 for reproductive phase and full maturity, respectively. The $\mathrm{C}: \mathrm{N}$ relationships with micronutrients at the reproductive phase were significant, negative, and for all micronutrients, except $\mathrm{Cu}$, specific for each growth stage, except with $\mathrm{Cu}$. Strong and negative relationships $(-0.25$ to $-0.39 ; p<0.05)$ were found between $\mathrm{C}: \mathrm{N}$ and each of $\mathrm{Fe}, \mathrm{Mn}$, and $\mathrm{Zn}$ at reproductive phase, but not at full maturity. Non-significant differences were found between growth stages $(p=0.46)$ and between predictors $(p=0.32)$, while the model accounted for a small portion $\left(R^{2}=0.26\right)$ of total variation. All of the slope estimates in the RMA functional relationship model were $>1.1$, while only $\mathrm{Cu}$ had a large $(0.65)$ Jackknifed $R^{2}$. Correlation coefficients for both sets of matrices were large $(r>0.90)$ and significant $(z<0.0001)$, while both growth stages were separated at a small $\left(D^{2}=6.7\right)$, but significant $(p<0.01)$ multivariate distance.

\subsubsection{Abiotic Stress Treatments}

Multiple comparisons were performed between two abiotic stress levels (NN: normal length of growing season and normal population density, and $\mathrm{NH}$ : normal length of growing season and high population density; Table 6) and between the contrasting abiotic stress treatments (i.e., SN: short growing season and normal population density, and $\mathrm{SH}$ : short growing season and high population density; Table 7). The NN-NH stress treatment comparison represents the single effect of high population density; while, the $\mathrm{SN}-\mathrm{SH}$ stress treatment comparison represents the single effect of short 
growing season and its joint effect with high population density. Coefficients of the calibration PLSR-1 model were comparable, and they accounted for similar validation variances for both of the stress treatments. Most (75.0\%) of the PLSR model coefficients for centered and scaled data were negative in both stress treatments; fertile tillers had the largest negative $(\mathrm{Cu},-0.377)$, while grain protein content the largest positive $(\mathrm{Cu}, 0.305)$ coefficients in $\mathrm{NN}$ and $\mathrm{NH}$ stress treatments, respectively.

Table 6. Multiple comparisons between two abiotic stress levels (NN: normal length of growing season and population density, and NH: normal length of growing season and high population density) of T. aestivum and T. durum, using partial least squares regression (PLSR), factor analyses, prediction of micronutrients as functions of phenotypic plasticities, multivariate distances, and matrix correlations between predictors and between predicted variables.

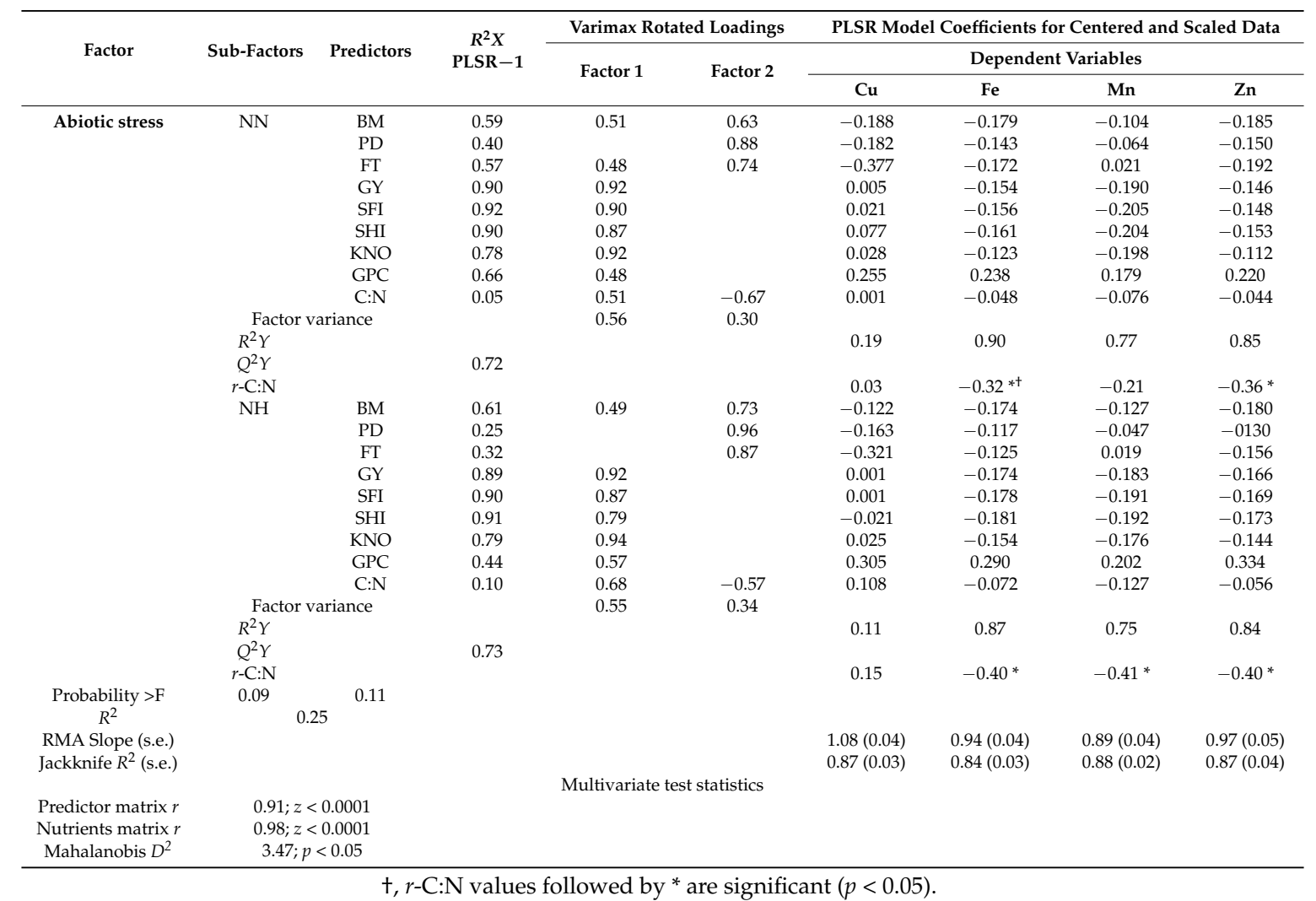

Similarities between NN and NH at several levels of comparison are illustrated in the almost identical loadings of independent variables on, and variance proportion accounted for, by Factor 1 (0.56 and 0.55) and Factor 2 (0.30 and 0.34), respectively. Correlation coefficients between C:N and micronutrients were typical of the majority of values encountered in previous analyses, with non-significant relationships with $\mathrm{Cu}$, and negative and mostly significant relationships with the remaining nutrients. The functional relationships between micronutrients indicated that only the RMA slop for $\mathrm{Cu}$ did not differ significantly from 1.0 (1.08 0.04); however, all of the Jackknifed $R^{2}$ estimates were exceptionally large. Based on univariate $(p=0.09)$ and multivariate $(p=0.11)$ statistical tests, there were no significant differences between $\mathrm{NN}$ and $\mathrm{NH}$. This conclusion was supported by the large correlation coefficients between matrices of predictor variables $(r=0.91)$ and between nutrient matrices $(r=0.98)$; both of which were highly significant $(z<0.0001)$; nevertheless, $\mathrm{NN}$ and NH were separated by a small, but significant multivariate distance $\left(D^{2}=3.47 ; p<0.05\right)$.

Comparisons between SN and SH (Table 7) indicated that the calibration PLSR-1 model coefficients were almost similar in magnitude; the model extracted $\leq 0.50$ of variation $\left(R^{2} Y\right)$ in each dependent variable in $\mathrm{SN}$, and slightly $>0.60$ of total variation in $\mathrm{Fe}$ and $\mathrm{Zn}$ for $\mathrm{SH}$, while, validation variances 
$\left(Q^{2} Y\right)$ were 0.65 and 0.62 for $\mathrm{SN}$ and $\mathrm{SH}$, respectively. Coefficients for centered and scaled data for each abiotic stress treatment were comparable in magnitude; the majority of which were negative in $\mathrm{SN}(77.8 \%)$ and $\mathrm{SH}(80.5 \%)$, with biomass exerting the largest negative effects on Fe and Zn. However, a few of the remaining coefficients were positive but small in magnitude (e.g., kernels $\mathrm{m}^{-2}$ ), while others were relatively large (e.g., grain protein content).

Independent variables in $\mathrm{SN}$ and $\mathrm{SH}$ that were loaded on two independent Factors with almost the same patterns, except for C:N, and explained 0.79 and 0.82 of total variation, respectively.

Table 7. Multiple comparisons between two abiotic stress levels (SN: short growing season and normal population density, and SH: short growing season and high population density) of T. aestivum and T. durum, using partial least squares regression (PLSR), factor analyses, prediction of micronutrients as functions of phenotypic plasticities, multivariate distances, and matrix correlations between predictors and between predicted variables.

\begin{tabular}{|c|c|c|c|c|c|c|c|c|c|}
\hline \multirow{3}{*}{ Factor } & \multirow{3}{*}{ Sub-Factors } & \multirow{3}{*}{ Predictors } & \multirow{3}{*}{$\begin{array}{c}R^{2} X \\
\text { PLSR-1 }\end{array}$} & \multicolumn{2}{|c|}{ Varimax Rotated Loadings } & \multirow{2}{*}{\multicolumn{4}{|c|}{$\begin{array}{c}\text { PLSR Model Coefficients for Centered and Scaled Data } \\
\text { Dependent Variables }\end{array}$}} \\
\hline & & & & \multirow{2}{*}{ Factor 1} & \multirow{2}{*}{ Factor 2} & & & & \\
\hline & & & & & & $\mathrm{Cu}$ & $\mathrm{Fe}$ & Mn & $\mathrm{Zn}$ \\
\hline \multirow{18}{*}{ Abiotic stress } & & PD & 0.60 & & 0.92 & -0.190 & -0.291 & -0.116 & -0.286 \\
\hline & & FT & 0.57 & 0.42 & 0.72 & -0.158 & -0.243 & -0.092 & -0.238 \\
\hline & & GY & 0.63 & 0.96 & & -0.058 & -0.078 & -0.144 & -0.082 \\
\hline & & SFI & 0.68 & 0.78 & & -0.047 & -0.060 & -0.151 & -0.066 \\
\hline & & GPC & 0.69 & 0.62 & & 0.118 & 0.320 & 0.090 & 0.303 \\
\hline & & C:N & 0.12 & -0.52 & & -0.131 & -0.215 & 0.069 & -0.203 \\
\hline & Factor $\mathrm{v}$ & ariance & & 0.44 & 0.35 & & & & \\
\hline & $R^{2} Y$ & & & & & 0.25 & 0.50 & 0.44 & 0.50 \\
\hline & $Q^{2} Y$ & & 0.65 & & & & & & \\
\hline & $r-\mathrm{C}: \mathrm{N}$ & & & & & 0.06 & -0.21 & $0.28^{*+}$ & -0.22 \\
\hline & $\mathrm{SH}$ & BM & 0.35 & & 0.71 & -0.207 & -0.516 & -0.157 & -0.453 \\
\hline & & $\mathrm{KNO}$ & 0.57 & 0.96 & & 0.001 & 0.068 & -0.099 & 0.026 \\
\hline & & GPC & 0.72 & 0.56 & & 0.225 & 0.320 & 0.194 & 0.341 \\
\hline & & C:N & 0.09 & & -0.68 & -0.082 & -0.256 & -0.011 & -0.206 \\
\hline & Factor v & ariance & & 0.49 & 0.33 & & & & \\
\hline & $R^{2} Y$ & & & & & 0.20 & 0.62 & 0.43 & 0.63 \\
\hline & $Q^{2} Y$ & & 0.62 & & & & & & \\
\hline & $r-\mathrm{C}: \mathrm{N}$ & & & & & 0.20 & -0.18 & 0.05 & -0.19 \\
\hline Probability $>\mathrm{F}$ & 0.08 & 0.03 & & & & & & & \\
\hline$R^{2}$ & 0. & & & & & & & & \\
\hline RMA Slope (s.e.) & & & & & & $1.04(0.07)$ & $1.06(0.11)$ & $1.12(0.11)$ & $1.02(0.08)$ \\
\hline Jackknife $R^{2}$ (s.e.) & & & & & & $0.63(0.09)$ & $0.26(0.12)$ & $0.19(0.15)$ & $0.37(0.12)$ \\
\hline & & & & \multicolumn{2}{|c|}{ Multivariate test statistics } & & & & \\
\hline Predictor matrix $r$ & $0.90 ; z$ & 0.0001 & & & & & & & \\
\hline Nutrients matrix $r$ & $0.90 ; z<$ & 0.0001 & & & & & & & \\
\hline
\end{tabular}

Relationships between $\mathrm{C}: \mathrm{N}$ and each of the micronutrients were small in magnitude and non-significant, except for Mn in SN $(r=0.28 ; p<0.05)$. Level of significance for univariate $(p=0.08)$ and multivariate $(p=0.03)$ statistical tests indicated that differences between the independent variables were significant, while those between SN and SH were marginally significant. The functional relationships between micronutrients due to both abiotic stresses indicated that all RMA slopes differed significantly from 1.0, except for Fe (1.12 \pm 0.11$)$; however, the only large Jackknifed $R^{2}$ estimate $(0.63)$ was found for $\mathrm{Cu}$. Matrix correlation between predictor variables and between micronutrients were both large $(r=0.90)$ and significant $(z<0.0001)$, but the multivariate distance separating $\mathrm{SN}$ and $\mathrm{SH}\left(D^{2}=1.39\right)$ was not significant $(p>0.05)$. 


\subsection{Confirmatory Factor Modeling of PPS}

Schematic representation of confirmatory factor analysis that is based on path coefficients (arrows with single heads) relating latent variables (oval shapes: nutrients, yield components, and yield) with observed variables (rectangle shapes), correlation coefficients between observed variables, and variance in latent variables explained by observed variables in two wheat genotypes representing T. durum and T. aestivum, at the end of stress phase II (SH-SP II) under maximum abiotic stress (SH, short growing season and high population density) as compared to the control at the end of stress Phase I (NN, normal length of growing season and normal population density; NN-SP I) are presented in Figure 6. Both wheat genotypes displayed similar trends in magnitude and direction of path and correlation coefficients of PPs within each CFA and for each latent variable at the start (NN-SP I) and the end (SH-SP II) of the experiment. Relatively small reductions in $R^{2}$ estimates (i.e., variance in latent variables, as explained by observed variables) of micronutrients (micronutrients index; from 0.95 to 87.7 for T. aestivum; and from 95.0 to 90.0 for T. durum) and yield components (yield components; from 82.4 to 73.6 in T. aestivum, and from 87.5 to 77.3 in T.durum), as latent variables, were found when compared with the large drop in $R^{2}$ estimates for grain yield (from 78.0 to $62.0 \mathrm{in}$ T. aestivum, and from 83.0 to 65.5 in T. durum) in both wheat genotypes. Relationships between latent variables followed the same trend, whereby the micronutrients index and yield components were negatively correlated but their coefficients differed in magnitude between wheat genotypes. The same trend was found for relationships between grain yield and yield components, and between grain yield and micronutrients index; however, the double abiotic stress treatment $(\mathrm{SH})$ resulted in major shifts in these relationships.

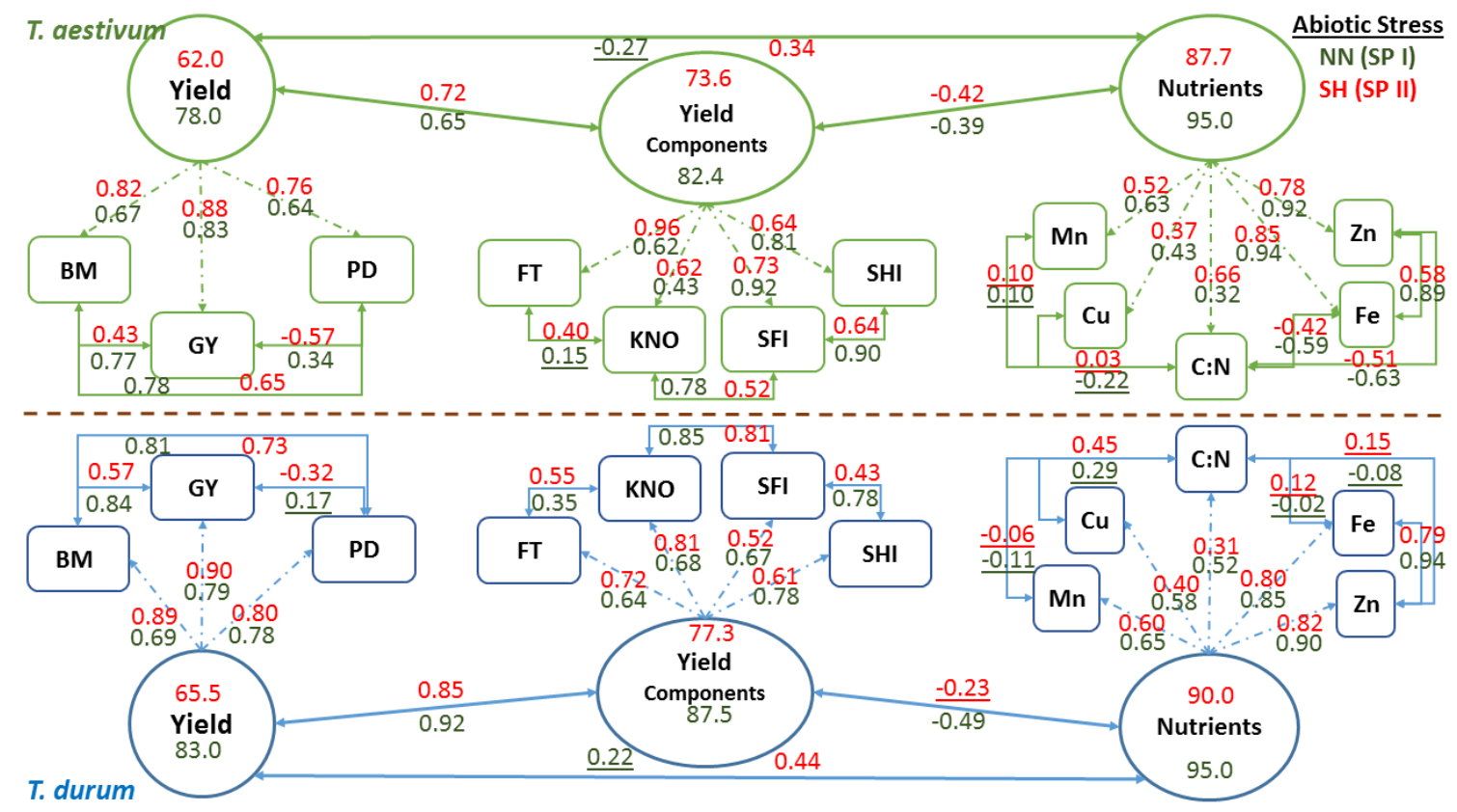

Figure 6. Schematic representation of confirmatory factor analysis based on path coefficients (arrows with single heads) relating latent variables (oval shapes: nutrients, yield components and yield) with observed variables (rectangles), correlation coefficients between observed variables, and variance in latent variables explained by observed variables in two wheat genotypes representing T. durum and $T$. aestivum at the end of stress phase II (SH-SP II) under maximum abiotic stress (SH, short growing season and high population density) compared to the control at the end of stress Phase I (NN, normal length of growing season and normal population density; NN-SP I). Underlined values are not significant; Tukey's HSD, $p>0.05$ ). [PP estimates of GCP were excluded from the analysis due to collinearity with C:N $(r=-0.98 ; p<0.0001)]$. 
Relationships between PPs of micronutrients and those of C:N were highly variable and mostly changed magnitude depending on wheat genotyp and the level of abiotic stress. Micronutrients expressed negative and large $r$ values between Fe and Zn with C:N in T. aestivum, but not in T. durum. Nevertheless, relationships among micronutrients were almost consistent in both wheat genotypes and declined in magnitude for SH-SP II as compared with NN-SPI. Path coefficients were larger for Fe and $\mathrm{Zn}$, as compared to $\mathrm{Cu}$ and $\mathrm{Mn}$ in both wheat genotypes; however, $\mathrm{C}: \mathrm{N}$ had the smallest path coefficients and their values exhibited opposite trends in wheat genotypes. Relationships between yield components and their path coefficients with their latent variable showed similar trends at both of the stress stages and for both wheat genotypes. All of the relationships between PPs of yield components were positive; their magnitudes declined at SH-SP II, especially between spike harvest index and spike fertility index; both of which had the smallest path coefficients with the latent variable in T. durum. Relationships between observed variables contributing to Yield, as a latent variable, were positive and significant, except those between population density and grain yield. Path coefficients, invariably, increased in magnitude at SH-SP II when compared to their original values at NN-SP I.

\section{Discussion}

Abiotic stresses, as triggered by climate change, are expected to impact crop production and food security of major food crops, including wheat. Fluctuations in wheat production due to weather and climate change can have a significant impact on the world wheat supply if future wheat cultivars are not tolerant to abiotic stresses [1,19]. Hence, a better understanding of the magnitude and direction of changes in wheat grain yield, its components, and their plasticity estimates would lead to more efficient manipulation of factors underlying the acquisition, use efficiency, and resource allocation within the wheat plant $[41,59,60]$. Plasticity of grain yield that involves a trade-off between yield potential and yield under abiotic stress has been reported for several small grain crops, including wheat [7].

Phenotypic plasticity is the major means by which plants cope with environmental heterogeneity. Although ubiquitous in nature [61], it is not universally maximal due to several inherent genetic variations and architectural constraints; and, external factors, such as water and nutrients limitation. However, arguments abound over the long-term role of PP, as an adaptation to short-term abiotic stresses, in facilitating evolutionary adaptation to climate change [15]. Observed plasticity in small grain crops range from a maximum of $100 \%$ for tillers per plant, to a minimum of $0.015-0.02$ for kernel weight; however, intermediate values have been reported for spikelets per spike $(0.20-0.30)$ and harvest index $(0.10-0.15)[27,36,62,63]$. The range of PPs in the current study $(0.52 \pm 0.04$ for $\mathrm{SHI}-0.93 \pm 0.03$ for KNO; Figure 1) was as large as, or even larger than, estimates that were reported for wheat under similar, or different abiotic stress conditions.

\subsection{Inter-and Intraspecific Variation in PPs}

Differences in PPs between the wheat genotypes are likely linked to the level of agronomic and genetic improvement that they underwent [21]. Stress phases caused a shift in frequency distributions of PPs, deviation from normality, and skewness in a few traits, and exposed many differences between the wheat genotypes in their reaction to abiotic stresses during both stress phases (Figure 1). Likewise, variation $\left(R^{2}\right)$ accounted for by differences between stress phases, although relatively small, exhibited a wide range ( 0.04 for $\mathrm{C}: \mathrm{N}$ ratio to 0.59 for $\mathrm{GCP})$. These differences may have been caused by differences in ploidy level, length of domestication history [20], or constitutive differences in resources allocation [12,13]. Resource constraints that were imposed on both wheat genotypes for six years triggered similar reaction trajectories, but with largely different magnitudes as demonstrated by other studies [16,17]. Of interest to wheat scientists are traits with narrow (e.g., spike fertility index) or wide range (e.g., biomass) of PPs that can be used as indicators of the buffering capacity of a crop under abiotic stress. 
Differences between wheat genotypes and between stress phases in frequency distribution, $R^{2}$ values, and the level of micronutrients density and protein content PPs are of special interest to wheat scientists in making agronomic and selection decisions under abiotic stress [22].

\subsection{Assessment of Agronomic and Micronutrient PPS}

Significant variances due to abiotic stress treatments suggested that both genotypes were plastic; while significant differences that were attributed to their two-way and three-way interactions (Table 2) indicated that they differed significantly in their plasticity estimates $[26,64,65]$. However, interaction term(s) can be significant (e.g., biomass due to growth stage $\times$ abiotic stress), even if the single term was not (e.g., biomass due to growth stage). Large variation in grain yield is expected if plasticity of fertile tillers is constrained by abiotic stress. This yield component was affected by all covariates, displayed a wide range of PSPD $(8.0 \%-100.0 \%)$, and had the largest plasticity $(0.86)$ among yield components (Table 3). Number of fertile tillers was identified as a critical component of grain yield stability under diverse environments; it contributes to resource acquisition (roots and leaves), and determines the potential number of spikes per plant (i.e., population density) [66,67].

Both wheat genotypes responded in tandem to population density through plastic responses of fertile tillers as the major component of plant architecture, and their PPs were positively correlated (Figure 3). Plastic responses of traits may be correlated, and several characters may show substantially different responses to the same abiotic stress [15]. Although negative relationships are the norm between phenotypic plasticities (due to trade-offs), hierarchies of positive correlations in the plasticity of agronomic, yield, and quality traits (Figure 3) are not uncommon [49]. For example, PPs of fertile tillers and kernels $\mathrm{m}^{-2}$ were closely clustered in both genotypes (Figure 2), and they responded similarly to stress phases, growth stages, and abiotic stress treatments. Also, PP of fertile tillers, being partly regulated by leaf area dynamics [68], is correlated with PP of grain yield because it leads to larger canopy leaf area and number of spikes $\mathrm{m}^{-2}$.

Mineral density in wheat kernels tends to decrease as grain yield increases [22]. In T. durum, the aleurone-to-endosperm ratio may become smaller due to a larger kernel weight, thus indirectly reducing grain mineral density [13]. Therefore, kernel weight could contribute to the negative relationship between grain yield and nutrient density. The predominantly negative PLSR model coefficients for micronutrient densities (75.0\%; Tables 3-6) suggested that the widely reported apparent dilution effect of decreased micronutrient density with increasing yield could be attributed to nutrient dilution across most yield components beyond kernel weight.

\subsection{Ontogeny Effects on PPS}

Plasticity may be constrained by its high (energy) cost, developmental factors, or unpredictable environmental cues regulating plant development [69]. Therefore, the decreasing plasticity of wheat in the order: fertile tillers $>$ kernels $\mathrm{m}^{-2}>$ kernel weight can be attributed to differential costs and contributions to yield components, stabilizing selection for kernel weight, and directional changes in resource (i.e., light, water, and nutrients) availability during plant ontogeny $[25,27]$. Tillering is a complex and dynamic wheat yield component; its plasticity is partly controlled by the regulation of plant leaf area dynamics, which determines the carbon balance during the vegetative growth stage $[67,68]$. As a major determinant of grain yield, tillers plasticity was impacted by environmental (PTQ), edaphic (ECa) stressors, and by most (77.0\%) covariates, fixed factors, and their interactions (Table 2); thus, ontogenically, tillering could be the most reliable yield component to use in selecting for tolerance to abiotic stress [35,62].

A major determinant of kernels $\mathrm{m}^{-2}$ in a cleistogamous plant, such as wheat, is the spike fertility index (i.e., number of fertile spikelets produced by the plant) $[39,70]$. Although kernels $\mathrm{m}^{-2}$ are usually negatively correlated with harvest index, but positively with grain yield (Figure 3), improvement of kernels $\mathrm{m}^{-2}$ is more likely to enhance grain yield due to increased dry matter allocation to wheat spikes at anthesis $[8,70]$. However, given no systematic progress in harvest index since the early 1990s, 
future yield gain will depend more on larger biomass [71], as well as the spike fertility index and the spike harvest index, both of which contribute to larger number of kernels $\mathrm{m}^{-2}$. Therefore, it can be suggested that the wheat plant can be redesigned for grain yield improvement under abiotic stress by manipulating traits that affect kernels $\mathrm{m}^{-2}$ (e.g., to tillering, number of florets per spikelet, and eventually spike fertility and harvest indices) without affecting grain size, thus raising the harvest index beyond its current maximum.

\subsection{Modeling Phenotypic Plasticity}

The reliability of building calibration and validation models, and estimating the effects of factor interactions (Table 2) was improved by applying all abiotic stress treatments for six years, a number required to be larger than the number of abiotic stress treatments for reliable estimates of model coefficients [41,52]. Robust estimates of PLSR coefficients and matrix correlations between dependent and independent variables (Tables 3-7) provided insights into multiple trait associations and identified how micronutrients were impacted by hierarchically classified stress factors and by different agronomic traits in both wheat genotypes.

\subsubsection{Wheat Genotypes}

Wheat species or genotypes with average grain yield plasticity are well-adapted to average-performing environments (i.e., with low GDD plasticity; [11]; however, above- and below-average grain yield plasticity can provide dynamic responses that are particularly advantageous under high- and low-yielding environments, respectively $[5,7,11]$. Averaged over six years of field experiments [43], and despite its larger yield potential, T. durum produced $25 \%-30 \%$ less grain yield than T. aestivum; whereas, grain yield, in accordance with earlier reports [20], was reduced by 28 and $23 \%$, respectively due to PS II when compared to PS I. Although T. durum has better water and nutrients use efficiencies under high-yielding environments and it tolerates abiotic stress better than T. aestivum, it has lower grain yield than T. aestivum under low-yielding environments [21,40]; however, both wheat genotypes responded similarly to changes in abiotic stresses in this and other studies [20]. It was speculated [72] that the constitutively larger kernel weight in T. durum is associated with its lower fruiting efficiency when compared with T. aestivum; nevertheless, kernels $\mathrm{m}^{-2}$ in both genotypes was the most sensitive yield component to abiotic stress in this and other studies $[39,73]$, presumably due to its larger plasticity and high heritability (Table 2). However, its negative relationships with grain protein content and micronutrients index (Figure 3) remains challenging.

\subsubsection{Stress Phases}

Wheat yield is at risk of abiotic stresses throughout plant development and until physiological maturity [48]. The season-long abiotic stress treatments that were used in the current study can be considered as abiotic stress priming, and they might have contributed to wheat resilience at the maturity stage. Abiotic stress priming at the vegetative growth stage was suggested as a field management tool to enhance stress tolerance of wheat to multiple abiotic stresses under future stress climates [31].

The Mahalanobis $D^{2}$ distance between stress phases $(68.9 ; p<0.001)$, although it explained almost the same validation variation in micronutrients $\left(Q^{2} Y=0.74\right.$ and 0.72$)$, was a clear indication of differential wheat responses to additional edaphic stress during SP I, and to the release of this stress during SP II. These differences can be attributed to population density, grain protein content and, in particular, to C:N ratio (Table 4). Large differences were found between SP I ( -0.06 to -0.22$)$ and SP II (-0.81 to 0.42$)$ in the magnitude and significance of C:N correlations, especially the negative and significant correlations with $\mathrm{Fe}, \mathrm{MN}$, and $\mathrm{Zn}$ under SP II, but not SP I. In addition, the non-significant correlation between predictor matrices $(r=0.57 ; z=0.18)$ in both stress phases is another indication of their differences; while, they impacted the closely correlated micronutrient matrices $(r=0.83 ; z<0.01)$ differently, as indicated by the slope ( $>1.0)$ of their functional relationships [57]. 


\subsubsection{Growth Stages}

Phenotypic plasticity was assessed at the reproductive and full maturity stages (Table 2; Figure 2); the former is an indicator of biological processes leading to the formation of grain yield [48]; while the latter is an indicator of the reproductive biology process determining spike fertility and spike harvest index $[73,74]$. Wheat developmental patterns play an important role in determining spike fertility index and kernels $\mathrm{m}^{-2}$; both yield components can be determined accurately by sampling a small number of individual spikes at crop maturity, thereby allowing for timely evaluation of many genotypes or treatments [34]. The duration of each growth phase can be influenced by abiotic stress [20]; thus, affecting the rate of sequentially developed yield components and their PPs. Growth stages differed markedly $(71.4 \%)$ in their PPs (Table 2) and at the discrimination level between and within wheat genotypes (Figure 2). Larger level of discrimination at FM than RP could be attributed to differences in the sequentially developed yield components, such as tiller $[20,69]$. The implications of differential plastic responses to the same abiotic stress as a function of growth stage (Figure 2) are of practical significance [31,48]. Reproductive plasticity (e.g., in spike fertility index, spike harvest index and kernels $\mathrm{m}^{-2}$ ) was demonstrated (Table 2) in response to resource limitations (e.g., caused by SN and $\mathrm{SH})$; however, plasticities of the final reproductive output (i.e., grain yield) and of biomass covaried in T. durum ( $r=0.92)$ and T. aestivum ( $r=0.75)$, but were totally non-overlapping (Figure 3 ).

\subsubsection{Abiotic Stress Treatments}

A wheat plant perception of, and response to even a single abiotic stress (e.g., limited water or nutrients) is dependent on several factors, such as the time of onset, severity, and duration [3], therefore, season-long, single, and double abiotic stresses were employed and contrasted with a control (i.e., no-stress treatment) for six years. A steady increase in population density has been a driver of maize- [74], sorghum- [68], but not wheat-yield improvements, where higher-yielding environments have maximum yields at higher population density. Despite the negative relationship between population density and fertile tillers $[32,69]$, their plasticity estimates covaried positively (Figure 3); thus, confirming that a trait and its plasticity can be independent, and PP is under its own genetic control under a specific abiotic stress [28].

Sowing date is an important decision for spring wheat production in northern latitudes due to its greater effect than population density on plant ontogeny and grain yield [17]. However, contrary to an earlier report [64], late sowing date at different population densities (i.e., $\mathrm{SN}$ and $\mathrm{SH}$ ) triggered changes in plasticity of fertile tillers and grain yield. Therefore, adjusting sowing date may confer useful adaptation to abiotic stress [71]. Nevertheless, manipulating the duration of the pre-anthesis growth phase remains an important goal of wheat breeding for improved adaptation and yield potential [31,71].

Shorter than normal-growing seasons, in addition to water stress close to maturity, are the main factors that presumably limit grain yield potential of spring wheat [17]. Delayed sowing, singly (SN treatment), or in combination with variable population density (SH treatment), explained almost similar variances $\left(Q^{2} Y\right.$; Table 7$)$, indicating that a short growing season may have stronger effect on PPs than a larger population density; the first deprives the crop from benefiting from available resources, while the effect of the second can be ameliorated by the tiller buffering capacity. Nevertheless, delayed sowing is a practical method for specific and genotypic comparisons under increasing abiotic stresses, as it may affect the developmental patterns and shift the timing and duration of critical growth stages $[17,60]$. Percent correct classification of SN and SH were $55 \%$ and $26 \%$, respectively, for T. durum, and $28 \%$ and $39 \%$, respectively, for T. aestivum. (Figure 2), suggesting that the wheat species exhibited some differences in reacting to these treatments. These differences were reflected on yield plasticity (Figure 4) and micronutrient index plasticity (Figure 5), in response to the interaction of these treatments with maturity stages in each genotype.

Increased population density would lead to aggressive competition between the genetically uniform wheat plants for decreasing resources, especially under shorter growing season; therefore, 
late-developed yield components during ontogeny (e.g., spike fertility and harvest indexes) will inevitably exhibit lower plasticity estimates [32,64]. High population density at a normal sowing date (NH treatment) in T. durum and T. aestivum exhibited sizable differences in its percent correct classification (32\% and 39\%, respectively) when contrasted with normal population density at normal sowing date (NN treatment) (61\% and 50\%, respectively) (Figure 2). These differences suggest that both genotypes reacted in the same manner to population density in the absence of abiotic stress caused by short growing season.

A steady increase in population density has been a strong driver of higher grain yield in corn [74]; however, higher population density of wheat may not achieve maximum grain yield in higher-yielding environment $[64,75]$. A density-dependent biomass partitioning strategy is a fundamental concept in plant population ecology that is applicable in wheat production [30].

High population density significantly impacted the grain yield of both genotypes by about $22.5 \%$ when compared to no-stress treatment [43]. However, crop species or genotypes that are least sensitive to differences in population density and length of growing season are the most sensitive to changes in nutrient status [12,22]. Sustained grain set mediated by large spike fertility index is paramount in maintaining yield potential under abiotic stress [8,51]; however, higher population density reduces both the number of floret primordia initiated and floret survival [32,64]; agronomically, this leads to the typical reaction of reduced individual spike fertility, as inferred from its PP, PCV, and GCV (Table 2). This reaction was attributed [73] to delayed spike growth that can be caused by a low red-to-far red ratio in the crop canopy [16].

\subsection{Confirmatory Factor Modeling of PPs}

Multivariate models, such as the confirmatory factor model, unlike univariate approaches, can be used to develop succinct, graphic, and comprehensive views of how traits within separate plant modules can affect the outcome of other traits and how they work together as a system to affect a final 'latent' variable (Figure 6). Coefficients of both models illustrate the divergence in multivariate mean among the wheat species [65]. Due to phenotypic integration being partly attributed to trait correlations, a plant phenotype must change in a coherent manner in response to one or more abiotic stresses. Random or undirected changes in one trait in relation to another may result in changes in plant fitness (i.e., GY and its plasticity; Table 2); while, phenotypic integration increases with increased abiotic stress [25]. Maximum abiotic stress (SH at SPP II) caused a parallel reduction in variances of all three 'latent' variables and their interrelationships in both wheat genotypes (Figure 6) [65]. The comprehensive inter- and intra-genotypic trait relationships (arrows with double heads) and path coefficients (arrows with a single head) summarize the similarities and differences between the wheat genotypes at contrasting abiotic stress levels. The latent variables in both wheat genotypes exhibited the largest variances, followed in decreasing order, by yield components and yield as the final output.

\section{Conclusions}

In view of climate change, a better understanding of the magnitude and direction of changes in wheat grain yield, its components, and their plasticity estimates would lead to more efficient manipulation of factors underlying the acquisition, use efficiency, and resource allocation under abiotic stresses. Comprehensive assessment of two wheat genotypic differences, representing two interrelated wheat species, in response to long-term abiotic stress, was adjusted for environmental and edaphic covariates at the reproductive and full maturity growth stages. The reproductive stage integrates crop response to abiotic stresses before anthesis; while, the full maturity stage integrates all responses to abiotic stresses, but mainly after anthesis. Phenotypic plasticities of durum and bread wheat genotypes were assessed under increasing abiotic and edaphic stresses that are mediated singly or in combination by $25 \%$ shorter growing seasons than normal, $25 \%$ larger population density, or both, for six years; validation and confirmatory factor models revealed major differences in phenotypic plasticities between genotypes that can be attributed to differences in ploidy level, length of domestication 
history, or constitutive differences in resources allocation. In addition, plasticity in wheat grain yield and its components impacted its quality traits, as measured by the plasticity of protein content and micronutrient densities. Both of the wheat species expressed inter- and intra-specific responses to long-term environmental and edaphic stresses, as evidenced by the wide range of phenotypic plasticity estimates $(0.52 \pm 0.04$ for spike harvest index to $0.93 \pm 0.03$ for kernels per unit area) of several traits. Genotypic differences in protein content and micronutrient densities, in addition to final grain yield, in response to abiotic stress are of special interest. Bread and durum wheat plants can be redesigned for grain yield improvement under abiotic stress by manipulating traits that affect kernels $\mathrm{m}^{-2}$ (e.g., number of tillers, number of florets per spikelet, and eventually spike fertility and harvest indices) without affecting grain size, thus raising harvest index beyond its current maximum, and raising grain yield potential under abiotic stress.

Funding: This research was funded by USDA-ARS.

Conflicts of Interest: The author declares no conflict of interest.

\section{Abbreviations}

\begin{tabular}{|c|c|}
\hline BM & Biomass \\
\hline CFA & Confirmatory Factor Analysis \\
\hline $\mathrm{C}: \mathrm{N}$ & Carbon-to-Nitrogen ratio \\
\hline $\mathrm{Cu}$ & Copper \\
\hline D2 & Mahalanobis squared distance \\
\hline $\mathrm{Fe}$ & Iron \\
\hline FM & Full maturity stage \\
\hline FT & Fertile Tillers \\
\hline GCV & Genotypic Coefficient of Variation \\
\hline GPC & Grain Protein Content \\
\hline GDD & Growing Degree Days \\
\hline GLM & General Linear Model \\
\hline GY & Grain Yield \\
\hline$h^{2}$ & Narrow-Sense Heritability \\
\hline KNO & Number of Kernels $\mathrm{m}^{-2}$ \\
\hline Mn & Manganese \\
\hline MNI & Micronutrients Index \\
\hline NH & Normal planting date-High population density \\
\hline NN & Normal planting date-Normal population density \\
\hline PCV & Phenotypic Coefficient of variation \\
\hline PD & Population Density (Plants $\mathrm{m}^{-2}$ ) \\
\hline PLRS & Partial Least Squares Regression \\
\hline PP & Phenotypic Plasticity \\
\hline PSPD & Percent Significant Pair-wise Differences (between means) \\
\hline RMA & Reduced Major Axis \\
\hline $\mathrm{RP}$ & Reproductive growth Phase \\
\hline SD & Standard Deviation \\
\hline s.e. & Standard error of the mean \\
\hline $\mathrm{SH}$ & Short growing season-High population density \\
\hline $\mathrm{SN}$ & Short growing season-Normal population density \\
\hline SP I & Stress Phase I \\
\hline SP II & Stress Phase II \\
\hline SFI & Spike fertility index \\
\hline SHI & Spike harvest index \\
\hline $\mathrm{Zn}$ & Zinc \\
\hline
\end{tabular}




\section{References}

1. Shiferaw, B.; Smale, M.; Braun, H.-J.; Duveiller, E.; Reynolds, M.; Muricho, G. Crops that feed the world 10. Past successes and future challenges to the role played by wheat in global food security. Food Secur. 2013, 5, 291-317. [CrossRef]

2. Anwar, M.R.; Li-Liu, D.; Farquharson, R.; Macadam, I.; Abadi, A.; Finlayson, J.; Wang, B.; Ramilan, T. Climate change impacts on phenology and yields of five broadacre crops at four climatologically distinct locations in Australia. Agric. Syst. 2015, 132, 133-144. [CrossRef]

3. Kissoudis, C.; van de Wiel, C.; Visser, R.G.F.; van der Linden, G. Future-proof crops: Challenges and strategies for climate resilience improvement. Curr. Opin. Plant Biol. 2016, 30, 47-56. [CrossRef] [PubMed]

4. Casadebaig, P.; Zheng, B.; Chapman, S.; Huth, N.; Faivre, R.; Chenu, K. Assessment of the potential impacts of wheat plant traits across environments by combining crop modeling and global sensitivity analysis. PLoS ONE 2016, 11, e0146385. [CrossRef] [PubMed]

5. Berger, J.; Palta, J.; Vadez, V. Review: An integrated framework for crop adaptation to dry environments: Responses to transient and terminal drought. Plant Sci. 2016, 253, 58-67. [CrossRef] [PubMed]

6. Gonzalez-Navarro, O.E.; Griffiths, S.; Molero, G.; Reynolds, M.P.; Slafer, G.A. Variation in developmental patterns among elite wheat lines and relationships with yield, yield components and spike fertility. Field Crops Res. 2016, 196, 294-304. [CrossRef] [PubMed]

7. Ferrante, A.; Cartelle, J.; Savin, R.; Slafer, G.A. Yield determination, interplay between major components and yield stability in a traditional and a contemporary wheat across a wide range of environments. Field Crops Res. 2017, 213, 114-127. [CrossRef]

8. Fischer, R.A. The effect of duration of the vegetative phase in irrigated semi-dwarf spring wheat on phenology, growth and potential yield across sowing dates at low latitude. Field crops Res. 2016, 198, 188-199. [CrossRef]

9. Li, P.-F.; Ma, B.-L.; Yan, W.; Cheng, Z.-G.; Li, F.-M.; Xiong, Y.-C. Plant architecture, plasticity, and adaptation strategies of two oat genotypes under different competition intensities. J. Sci. Food Agric. 2016, 96, 1431-1439. [CrossRef] [PubMed]

10. Forsman, A. Rethinking phenotypic plasticity and its consequences for individual, population and species. Heredity 2015, 115, 276-284. [CrossRef] [PubMed]

11. Grogan, S.M.; Anderson, J.; Baenziger, P.S.; Frels, K.; Guttieri, M.J.; Haley, S.D.; Kim, K.-S.; Liu, S.; McMaster, G.S.; Newell, M.; et al. Phenotypic plasticity of winter wheat heading date and grain yield across the US Great Plains. Crop Sci. 2016, 56, 1-14. [CrossRef]

12. Ng'oma, E.; Perinchery, A.M.; King, E.G. How to get the most bang for your buck: The evolution and physiology of nutrition-dependent resource allocation strategies. Proc. R. Soc. B 2017, 284. [CrossRef] [PubMed]

13. Guttieri, M.J.; Baenziger, P.S.; Frels, K.; Carver, B.; Arnall, B.; Waters, B.M. Variation for grain mineral concentration in a diversity panel of current and historical Great Plains hard winter wheat germplasm. Crop Sci. 2015, 55, 1035-1052. [CrossRef]

14. Messier, J.; Lechowicz, M.J.; McGill, B.J.; Violle, C.; Enquist, B.J. Interspecific integration of trait dimensions at local scales: The plant phenotype as an integrated network. J. Ecol. 2017. [CrossRef]

15. Oostra, V.; Saastamoinen, M.; Zwaan, B.J.; Wheat, C.W. Strong phenotypic plasticity limits potential for evolutionary responses to climate change. Nat. Commun. 2018, 9. [CrossRef] [PubMed]

16. Mirabella, N.E.; Abbate, P.E.; Ramirez, I.A.; Potaroli, A.C. Genetic variation for wheat spike fertility in cultivars and early breeding materials. J. Agric. Sci. 2016, 154, 13-22. [CrossRef]

17. He, Y.; Wang, H.; Qian, B.; McConkey, B.; DePauw, R. How early can the seeding dates of spring wheat be under current and future climate in Saskatchewan, Canada? PLoS ONE 2012, 7, e45153. [CrossRef] [PubMed]

18. Elía, M.; Savin, R.; Slafer, G.A. Fruiting efficiency in wheat: Physiological aspects and genetic variation among modern cultivars. Field Crops Res. 2016, 191, 83-90. [CrossRef]

19. Qian, B.; De Jong, R.; Huffman, T.; Wang, H.; Yang, J. Projecting yield changes of spring wheat under future climate scenarios on the Canadian Prairies. Theor. Appl. Climatol. 2016, 123, 651-669. [CrossRef]

20. Wang, J.-Y.; Turner, N.C.; Liu, Y.X.; Siddique, K.H.M.; Xiong, Y.C. Effects of drought stress on morphological, physiological and biochemical characteristics of wheat species differing in ploidy level. Funct. Plant Biol. 2017, 44, 219-234. [CrossRef] 
21. Daryanto, S.; Wang, L.; Jacinthe, P.-A. Global synthesis of drought effects on cereal, legume, tuber and root crops production: A review. Agric. Water Manag. 2017, 179, 18-33. [CrossRef]

22. Matesanz, S.; Milla, R. Differential plasticity to water and nutrients between crops and their wild relatives. Environ. Exp. Bot. 2018, 145, 54-63. [CrossRef]

23. Upadhyaya, H.D.; Dwivedi, S.L.; Vetriventhan, M.; Krishnamurthy, L.; Singh, S.K. Post-flowering drought tolerance using managed stress trials, adjustment to flowering, and mini core collection in sorghum. Crop Sci. 2017, 57, 310-321. [CrossRef]

24. Thiry, A.A.; Dulanto, P.N.C.; Reynolds, M.P.; Davies, W.J. How can we improve crop genotypes to increase stress resilience and productivity in a future climate? A new crop screening method based on productivity and resistance to abiotic stress. J. Exp. Bot. 2016, 67, 5593-5603. [CrossRef] [PubMed]

25. DeWitt, T.J.; Sih, A.; Wilson, D.S. Costs and limits of phenotypic plasticity. Trends Ecol. Evol. 1998, $13,77-81$. [CrossRef]

26. Nikotra, A.B.; Atkin, O.K.; Bonser, S.P.; Davidson, A.M.; Finnegan, E.J.; Mathesius, U.; Poot, P.; Purugganan, M.D.; Richards, C.L.; Valladares, F.; et al. Plant phenotypic plasticity in a changing climate. Trends Plant Sci. 2011, 15, 684-692. [CrossRef] [PubMed]

27. Labra, M.H.; Struik, P.C.; Evers, J.B.; Calderini, D.F. Plasticity of seed weight compensates reductions in seed number of oilseed rape in response to shading at flowering. Europ. J. Agron. 2017, 84, 113-124. [CrossRef]

28. Bradshaw, A. Evolutionary significance of phenotypic plasticity in plants. Adv. Genet. 1965, 13, 115-155. [CrossRef]

29. Jaradat, A.A. The integrated phenotype and plasticity of Cuphea PSR23: A semi-domesticated oilseed crop. Commun. Biom. Crop Sci. 2016, 11, 10-30.

30. Pigliucci, M. Evolution of phenotypic plasticity: Where are we going? Trends Ecol. Evol. 2005, 20, 481-486. [CrossRef] [PubMed]

31. Liu, S.; Li, X.; Larsen, D.H.; Zhu, X.; Song, F.; Liu, F. Drought priming at vegetative growth stage enhances nitrogen-use efficiency under post-anthesis drought and heat stress in wheat. J. Agron. Crop Sci. 2017, 203, 29-40. [CrossRef]

32. Tokatlidis, I.S. Crop adaptation to density to optimize grain yield: Breeding implications. Euphytica 2017, 213. [CrossRef]

33. Des Marais, D.L.; Lasky, J.R.; Verslues, P.E.; Chang, T.Z.; Juenger, T.E. Interactive effects of water limitation and elevated temperature on the physiology, development and fitness of diverse accessions of Brachypodium distachyon. New Phytol. 2017, 214, 132-144. [CrossRef] [PubMed]

34. Abbate, P.E.; Pontaroli, A.C.; Lazaro, L.; Gutheim, F. A method of screening for spike fertility in wheat. J. Agric. Sci. 2013, 151, 322-330. [CrossRef]

35. Kumar, U.; Laza, M.R.; Soulié, J.-C.; Pascoa, R.; Mendez, K.V.S.; Dingkuhn, M. Compensatory phenotypic plasticity in irrigated rice: Sequential formation of yield components and simulation with SAMARA model. Field Crops Res. 2016, 193, 164-177. [CrossRef]

36. Martino, D.L.; Abbate, P.E.; Cendoya, M.G.; Gutheim, F. Wheat spike fertility: Inheritance and relationship with spike yield components in early generations. Plant Breed. 2015, 134, 264-270. [CrossRef]

37. Palacio-López, K.; Beckage, B.; Scheiner, S.; Molofsky, J. The ubiquity of phenotypic plasticity in plants: A synthesis. Ecol. Evol. 2015, 5, 3389-3400. [CrossRef] [PubMed]

38. Sadras, V.O.; Reynolds, M.P.; de la Vega, A.J.; Petrie, P.R.; Robinson, R. Phenotypic plasticity of yield and phenology in wheat, sunflower and grapevine. Field Crop Res. 2009, 110, 242-250. [CrossRef]

39. Gonzalez, F.G.; Terrile, I.I.; Falcon, M.O. Spike fertility and duration of stem elongation as promising traits to improve potential grain number (and yield): Variation in modern Argentinean wheats. Crop Sci. 2015, 51. [CrossRef]

40. Marti, J.; Slafer, G.A. Bread and durum wheat yields under a wide range of environmental conditions. Field Crops Res. 2014, 156, 258-271. [CrossRef]

41. Sadras, V.O.; Slafer, G.A. Environmental modulation of yield components in cereals: Heritabilities reveal a hierarchy of phenotypic plasticities. Field Crops Res. 2012, 127, 215-224. [CrossRef]

42. Barros, J.A.; Machado, R.C.; Amaral, C.D.B.; Schiavo, D.; Nogueira, A.R.A.; Nóbrega, J.A. Plant Nutrient Analysis Using the Agilent 5100 Synchronous Vertical Dual View ICP OES; Application Note, Food Testing and Agriculture. Available online: http:/ / www.agilent.com (accessed on 20 September 2017). 
43. Jaradat, A.A. Modeling biomass allocation and grain yield in bread and durum wheat under abiotic stress. Aust. J. Crop Sci. 2009, 3, 237-248.

44. Lewis, R.R.; DeMartelaere, D.E.; Miller, E.L. Soil Conservation Service. Soil Survey Stevens County, Minnesota; United States Department of Agriculture-Soil Conservation Service (USDA-SCS): Washington, DC, USA, 1971.

45. Weather: USDA ARS. Available online: https://www.ars.usda.gov/midwest-area/morris-mn/soilmanagement-research/docs/weather/ (accessed on 10 May 2018).

46. Ortiz-Monasterio, I.; Dhillon, S.S.; Fischer, R.A. Date of sowing effects on grain yield and yield components of irrigated spring wheat cultivars and relationships with radiation and temperature in Ludhiana, India. Field Crops Res. 1994, 37, 169-184. [CrossRef]

47. Zadoks, J.C.; Chang, T.T.; Konzak, C.F. A decimal code for the growth stages of cereals. Weed Res. 1974, 14, 415-421. [CrossRef]

48. Barber, H.M.; Carney, J.; Alghabari, F.; Gooding, M.J. Decimal growth stages for precision wheat production in changing environments? Ann. Appl. Biol. 2015, 166, 355-371. [CrossRef]

49. Peltonen-Sainio, P.; Jauhiainena, L.; Sadras, V.O. Phenotypic plasticity of yield and agronomic traits in cereals and rapeseed at high latitudes. Field Crops Res. 2011, 124, 261-269. [CrossRef]

50. Eberhart, S.A.; Russell, W.A. Stability parameters for comparing varieties. Crop Sci. 1966, 6, 36-40. [CrossRef]

51. Kumar, U.; Laza, M.R.; Soulié, J.-C.; Pascoa, R.; Mendez, K.V.S.; Dingkuhn, M. Analysis and simulation of phenotypic plasticity for traits contributing to yield potential in twelve rice genotypes. Field Crops Res. 2017, 202, 94-107. [CrossRef]

52. Payne, W. Developments from analysis of variance through to generalized linear models and beyond. Ann. Appl. Biol. 2014, 164, 11-17. [CrossRef]

53. $J M P^{\circledR}$ Pro. Version 13.2.0; SAS Institute Inc.: Cary, NC, USA, 2016.

54. TIBCO Statistica, Data Analysis Software Systems, version 13.3; TIBCO Software Inc.: Palo Alto, CA, USA, 2017.

55. Rohlf, F.J. NTSYS-pc-Numerical Taxonomy and Multivariate Analysis System; Applied Biostatistics Inc.: New York, NY, USA, 2009; ISBN 0-925031-31-3.

56. Gu, F. Analysis of correlation matrices using scale-invariant common principal component models and a hierarchy of relationships between correlation matrices. Struct. Equ. Model. A Multidiscip. J. 2016, 23, 819-826. [CrossRef]

57. Niklas, K.J.; Hammond, S.T. Assessing scaling relationships: Uses, abuses, and alternatives. Int. J. Plant. Sci. 2014, 175, 754-763. [CrossRef]

58. Jöreskog, K.; Sörbom, D. LISREL 9.30; Scientific Software International, Inc.: Chicago, IL, USA, 2017.

59. Sadras, V.O.; Rebetzke, G.J.; Edmeades, G.O. The phenotype and the components of phenotypic variance. Field Crops Res. 2013, 154, 255-259. [CrossRef]

60. Sadras, V.O.; Vadez, V.; Purushothaman, R.; Lake, L.; Marrou, H. Unscrambling confounded effects of sowing date trials to screen for crop adaptation to high temperature. Field Crops Res. 2015, 177, 1-8. [CrossRef]

61. Valladares, F.; Gianoli, E.; Góme, J.M. Ecological limits to plant phenotypic plasticity. New Phytol. 2007, 176, 749-763. [CrossRef] [PubMed]

62. Sanad, M.N.; Campbell, K.G.; Gill, K.S. Developmental program impacts phenological plasticity of spring wheat under drought. Bot. Stud. 2016, 57, 35-46. [CrossRef] [PubMed]

63. Zhang, S.; Wang, L.; Ma, F.; Yang, J.; Atkin, O.K. Phenotypic plasticity in rice: Responses to fertilization and inoculation with arbuscular mycorrhizal fungi. J. Plant Ecol. 2015, 9, 107-116. [CrossRef]

64. Dornbusch, T.; Baccar, R.; Watt, J.; Hillier, J.; Bertheloot, J.; Fournier, C.; Andrieu, B. Plasticity of winter wheat modulated by sowing date, plant population density and nitrogen fertilization: Dimensions and size of leaf blades, sheaths and internodes in relation to their position on a stem. Field Crops Res. 2011, 121, 116-124. [CrossRef]

65. Walter, G.M.; Aguirre, J.D.; Blows, M.W.; Ortiz-Barrientos, D. Evolution of genetic variance during adaptive radiation. Am. Nat. 2018, 191, E108-E128. [CrossRef] [PubMed]

66. Xu, H.-C.; Cai, T.; Wang, Z.-L.; He, M.-R. Physiological basis for the differences of productive capacity among tillers in winter wheat. J. Integr. Agric. 2015, 14, 1958-1970. [CrossRef]

67. Moellelr, C.; Rebetzke, G. Performance of spring wheat lines near-isogenic for the reduced-tillering 'tin' trait across a wide range of water-stress environment-types. Field Crop Res. 2017, 200, 96-113. 
68. Alam, M.M.; van Oosterm, E.J.; Cruickshank, A.W.; Jordan, D.R.; Hammer, G.L. Predicting tillering of diverse sorghum germplasm across environments. Crop Sci. 2017, 57, 78-87. [CrossRef]

69. Kumar, P.V.; Rao, V.U.; Bhavan, O.; Dubey, A.P.; Singh, C.B. Effect of temperature and photothermal quotient on the yield components of wheat (T. aestivum L.) in Indo-Gangetic Plains of India. Exp. Agric. 2016, 52, 14-35. [CrossRef]

70. Slafer, G.A.; Savin, R.; Sadras, V.O. Coarse and fine regulation of wheat yield components in response to genotype and environment. Field Crops Res. 2014, 157, 71-83. [CrossRef]

71. Xie, Q.; Mayes, S.; Sparkes, D.L. Pre-anthesis biomass accumulation of plant and plant organs defines yield components in wheat. Eur. J. Agron. 2016, 81, 15-26. [CrossRef]

72. Slafer, G.A.; Elia, M.; Savin, R.; García, G.A.; Terrile, I.I.; Ferrante, A.; Miralles, D.J.; González, F.G. Fruiting efficiency: An alternative trait to further rise wheat yield. Food Energy Secur. 2015, 4, 92-109. [CrossRef]

73. Guo, Z.; Slafer, G.A.; Schnurbusch, T. Genotypic variation in spike fertility traits and ovary size as determinants of floret and grain survival rate in wheat. J. Exp. Bot. 2016. [CrossRef] [PubMed]

74. Amelong, A.; Hernández, F.; Novoa, A.D.; Borrás, L. Maize stand density yield response of parental inbred lines and derived hybrids. Crop Sci. 2017, 57, 32-39. [CrossRef]

75. Masuya, Y.; Shimono, H. Mining a yield-trial database to identify high-yielding cultivars by simulation modeling: A case study for rice. J. Agric. Meteorol. 2017, 73, 51-58. [CrossRef]

(C) 2018 by the author. Licensee MDPI, Basel, Switzerland. This article is an open access article distributed under the terms and conditions of the Creative Commons Attribution (CC BY) license (http://creativecommons.org/licenses/by/4.0/). 